\title{
Serpentes do Município de Viçosa, Mata Atlântica do Sudeste do Brasil
}

\author{
Henrique Caldeira Costa ${ }^{1,3}$, Davi Lima Pantoja ${ }^{2}$, José Lélis Pontes ${ }^{1}$ \& Renato Neves Feio ${ }^{1}$ \\ ${ }^{1}$ Museu de Zoologia João Moojen, Vila Gianetti, 32, Universidade Federal de Viçosa - UFV, \\ CEP 36570-000, Viçosa, MG, Brasil \\ ${ }^{2}$ Departamento de Zoologia - IB, Campus Darcy Ribeiro, Universidade de Brasília - UnB, \\ CEP 70910-900, Brasília, DF, Brasil \\ ${ }^{3}$ Autor para correspondência: Henrique Caldeira Costa, e-mail: ccostah@yahoo.com.br
}

COSTA, H.C., PANTOJA, D.L., PONTES, J.L. \& FEIO, R.N. Snakes of the Municipality of Viçosa, Atlantic Forest of Southeastern Brazil. Biota Neotrop. 10(3): http://www.biotaneotropica.org.br/v10n3/en/abstract?in ventory+bn03610032010.

\begin{abstract}
Based on specimens housed in scientific collections, we present here a list of snake species from the Municipality of Viçosa, which is located in an Atlantic Forest portion of the State of Minas Gerais, Southeastern Brazil. Thirty four species were confirmed in Viçosa. Two others have uncertain reports and five that were registered in neighboring municipalities could also occur in Viçosa. Information concerning snakes distribution and natural history is also presented, based on scientific literature data and sporadic field observations in the study area. In general, we can consider that the snake fauna of Viçosa is comprised of species which are able to use environments modified by human action, though some of them are dependent on the remaining forest fragments. Fieldwork is still required to improve the knowledge of snake species richness in forest fragments, to confirm the presence of species with uncertain records and potential occurrence in Viçosa, and to investigate the possibility of population declines of those species without records from the last decade.
\end{abstract}

Keywords: inventory, Zona da Mata, Minas Gerais.

COSTA, H.C., PANTOJA, D.L., PONTES, J.L. \& FEIO, R.N. Serpentes do Município de Viçosa, Mata Atlântica do Sudeste do Brasil. Biota Neotrop. 10(3): http://www.biotaneotropica.org.br/v10n3/pt/abstract?in ventory+bn03610032010.

Resumo: Apresentamos aqui, com base em exemplares depositados em coleções científicas, uma lista das espécies de serpentes do Município de Viçosa, localizado em uma porção da Mata Atlântica do Estado de Minas Gerais, Sudeste do Brasil. Trinta e quatro espécies foram confirmadas em Viçosa. Outras duas possuem registros duvidosos e cinco espécies que foram registradas em municípios vizinhos poderiam também ocorrer em Viçosa. Informações sobre distribuição e história natural das serpentes são apresentadas, baseadas em dados da literatura científica e observações esporádicas na área de estudo. Podemos considerar que de maneira generalizada a fauna de serpentes de Viçosa é constituída por espécies com condições de utilizar ambientes antropizados, mas algumas são dependentes dos fragmentos florestais ainda existentes. Estudos de campo ainda são necessários para aprimorar o conhecimento sobre a riqueza de espécies de serpentes nos fragmentos florestais, para confirmar a presença das espécies com registros incertos e ocorrência potencial em Viçosa, e para investigar a possibilidade de declínio populacional daquelas espécies sem registros há mais de uma década.

Palavras-chave: inventário, Zona da Mata, Minas Gerais. 


\section{Introdução}

A maior parte da diversidade mundial de répteis e anfíbios está concentrada nas regiões tropicais (Zug et al. 2001), cujas paisagens naturais estão sendo destruídas rapidamente pela ocupação humana. Na região Neotropical, cabe a contradição à Floresta Tropical Atlântica (Mata Atlântica) de ser simultaneamente um dos biomas mais diversos e ameaçados do planeta, tornando-se uma das áreas prioritárias para conservação da biodiversidade mundial (Myers et al. 2000, Mittermeier et al. 2004). Ao mesmo tempo em que abriga um expressivo número de endemismos (40\% das espécies de plantas e $30 \%$ das de vertebrados conhecidas para o bioma) (Mittermeier et al. 2004), a Mata Atlântica tem hoje sua cobertura vegetal reduzida a $7,6 \%$ da extensão original, criando uma paisagem em mosaico, formada por fragmentos com diferentes tamanhos e graus de conservação (Fundação... \& Instituto... 2008).

Os anfíbios e répteis são considerados modelos ideais para estudos sobre os efeitos da fragmentação (Silvano et al. 2003), mas ainda se sabe pouco, sobretudo quanto às taxocenoses de serpentes. Atualmente, conhecemos mais de 3.000 espécies de serpentes viventes no mundo (Uetz 2008), das quais mais de 370 ocorrem no Brasil (Bérnils 2010). Na Mata Atlântica já foram registradas mais de 130 espécies de serpentes (Rodrigues 2005), e as informações sobre localidades específicas, em geral ainda são pontuais (e.g. Franco et al. (1998), Argôlo (2004) e Santana et al. (2008) no Nordeste, Sazima \& Haddad (1992), Marques \& Sazima (2004) e Pontes \& Rocha (2008) no Sudeste, Bérnils et al. (2001) e Bernarde \& Machado (2002) no Sul do Brasil).

O Estado de Minas Gerais, no Sudeste do Brasil, tem 49\% de sua área originalmente coberta pela Mata Atlântica (equivalente a quase 29 milhões de hectares), da qual, devido à devastação ambiental desde o período colonial brasileiro, restam apenas 9,6\% (Fundação...
\& Instituto... 2008). A despeito da pequena área remanescente, o conhecimento sobre a ofidiofauna atlântica e de áreas de transição de Minas Gerais ainda é incipiente, estando restrito a poucos inventários (alguns preliminares) (e.g. Bernardes et al. 1994, Feio \& Caramaschi 2002, Bertoluci et al. 2009, Palmuti et al. 2009, São-Pedro \& Pires 2009) e registros isolados de ampliação de distribuição geográfica de determinadas espécies (e.g. Prudente \& Feio 2001, Passos \& Brandão 2002, Silveira et al. 2004a,b, Carvalho-Junior \& Nascimento 2005, Dias et al. 2008, Costa et al. 2009b).

As listas de espécies têm se prestado aos ecólogos e tomadores de decisões conservacionistas como uma valiosa ferramenta (Droege et al. 1998) e podem fornecer informações em escala local, regional e continental, possibilitando estudos futuros sobre tendências populacionais, estrutura de comunidades, estimativas de riqueza de espécies e padrões biogeográficos. Mais especificamente, o estudo da riqueza e composição de espécies tem importância primária para se conhecer o funcionamento das comunidades biológicas, sendo também a base para a compreensão da dinâmica entre fragmentos e orientadora para muitas medidas conservacionistas (Droege et al. 1998, Haddad 1998). Nesse contexto, o presente estudo apresenta um levantamento das espécies de serpentes do Município de Viçosa, na Mata Atlântica de Minas Gerais, Sudeste do Brasil.

\section{Material e Métodos}

\section{1. Área de estudo}

O Município de Viçosa (20 45’ S e 42 $2^{\circ} 52^{\prime}$ O) (Figura 1) localizase na Mata Atlântica de Minas Gerais, Sudeste do Brasil, numa região conhecida como "Zona da Mata". Originalmente a Zona da Mata formava um contínuo com as florestas do médio Rio Paraíba ao Sul,

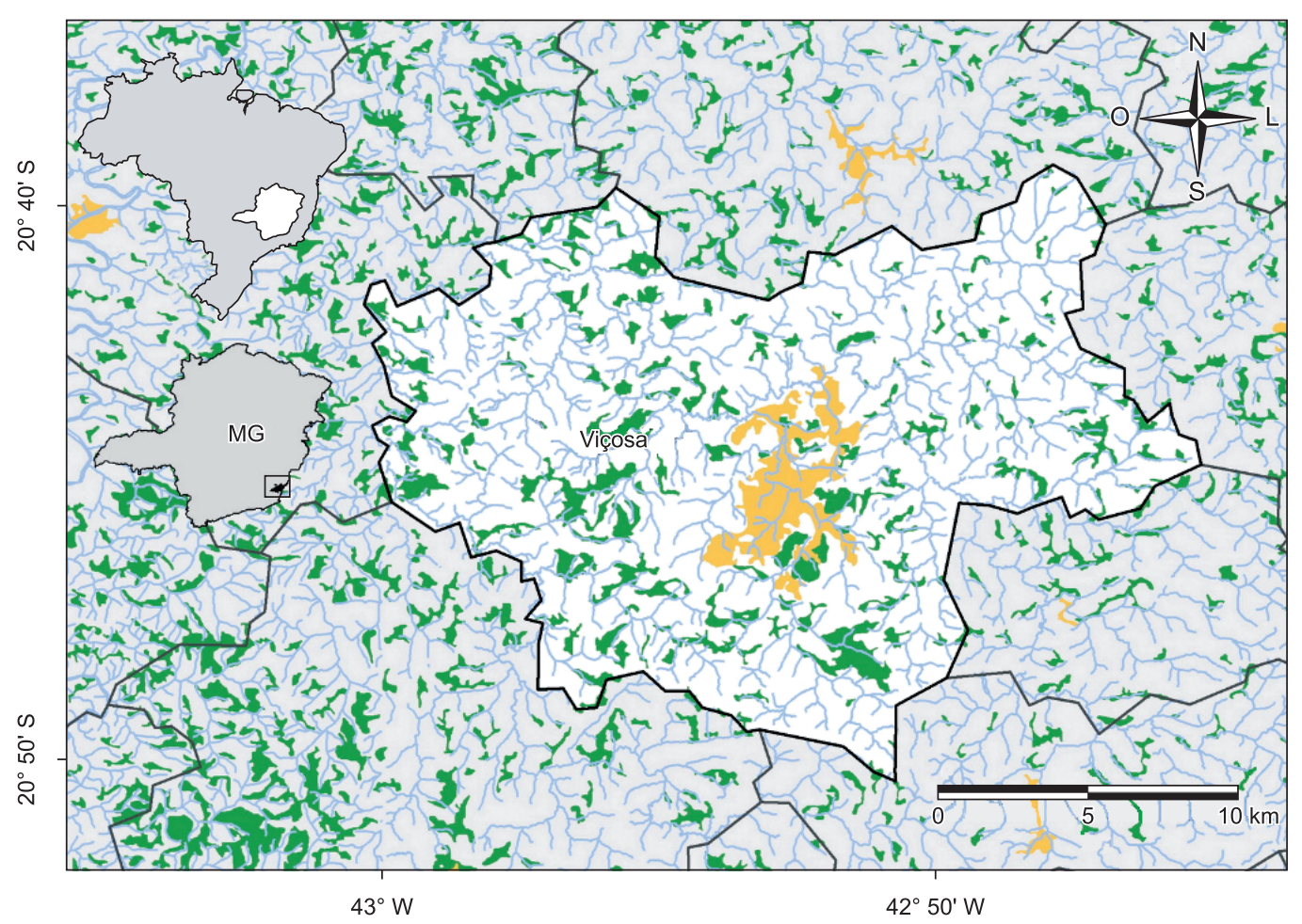

Figura 1. Mapa da área de estudo, Município de Viçosa, Mata Atlântica do Estado de Minas Gerais, Sudeste do Brasil. Áreas verdes = áreas florestadas; Áreas amarelas = área urbana.

Figure 1. Map of the study site, Municipality of Viçosa, Atlantic Forest of the State of Minas Gerais, Southeastern Brazil. Green areas = forested areas; Yellow areas $=$ urban areas. 
e do vale do Rio Doce ao Norte, sendo limitada a Oeste pelos campos naturais do Centro e Sul do Estado (Valverde 1958). Com uma área total de quase 30 mil hectares (Instituto... 2007) drenados pela bacia do Rio Turvo Sujo e a microbacia do Ribeirão São Bartolomeu (Fontes et al. 2006), a vegetação nativa de Viçosa constitui-se de formações de floresta estacional semidecidual montana e submontana (Coelho et al. 2005). As altitudes variam entre 550 e $750 \mathrm{~m}$ acima do nível do mar (Ribon et al. 2003). O clima é mesotérmico úmido, classificado como tipo Cwa no sistema de Köppen, com verões chuvosos, invernos secos, e a temperatura média do mês mais quente do ano superior a $22{ }^{\circ} \mathrm{C}$ (Vianello \& Alves 1991). A temperatura média anual é de $19,4{ }^{\circ} \mathrm{C}$ (variando entre 14,8 e $26,4^{\circ} \mathrm{C}$ ) e a precipitação média anual é de 1.221,40 mm (Departamento Nacional de Meteorologia 1992).

O Município de Viçosa vem sendo explorado desde o início do século XIX quando nele se fixaram os primeiros colonos, oriundos das regiões auríferas de Ouro Preto e Mariana (Pereira 2005). A extração de ouro se encontrava em decadência, levando a um processo de migração em busca de boas terras para lavoura, e a atividade agrária (sobretudo a cafeicultura) foi responsável pelo primeiro impulso na economia local (Pereira 2005). Assim teve início a mudança da paisagem viçosense, restringindo as florestas aos morros e encostas mais altas (Valverde 1958). Este na verdade é o retrato do desenvolvimento na Zona da Mata como um todo, onde uma das principais características atuais, paradoxalmente, é a falta de matas (Valverde 1958).

Na década de 1920, Viçosa adentra uma nova fase com a instalação da Escola Superior de Agricultura e Veterinária (atual Universidade Federal de Viçosa - UFV), que se torna o elemento central e impulsionador da urbanização (de forma geral, desordenada) do município (Pereira 2005). A partir da década de 1930 o número de fragmentos florestais na região parece ter aumentado, resultante da regeneração de antigos cafezais abandonados (Ribon et al. 2003). Atualmente, a paisagem de Viçosa encontra-se ocupada predominantemente por pastagens (Coelho et al. 2005), e as florestas foram reduzidas a 7.000 ha $(32,6 \%$ da área total do município) (Instituto... 2007), a imensa maioria delas (mais de 99\%) secundária, com 20-60 anos de regeneração (Ribon et al. 2003).

\section{Coleta de dados}

Os registros apresentados provêm de consultas às coleções com maior potencialidade como depositárias de espécimes procedentes de Viçosa, conforme listadas a seguir: 1) Museu de Zoologia João Moojen, Universidade Federal de Viçosa (MZUFV), Viçosa, MG; 2) Fundação Ezequiel Dias (FUNED), Belo Horizonte, MG; 3) Coleção Herpetológica Alphonse Richard Hoge do Instituto Butantan (IBSP), São Paulo, SP; e 4) Museu de Zoologia da Universidade de São Paulo (MZUSP), São Paulo, SP.

Para identificação dos espécimes foram utilizados, além de consultas a especialistas, os seguintes trabalhos: Peters \& OrejasMiranda (1970), Thomas (1976), Thomas \& Dixon (1977), Dixon \& Kofron (1983), Vanzolini (1986), Dixon (1989), Grantsau (1991), Di-Bernardo (1992), Zaher \& Caramaschi (1992), Dixon et al. (1993), Scrocchi \& Druz (1993), Scrocchi et al. (1993), Silva-Jr. \& Sites (1999), Marques et al. (2001), Franco \& Ferreira (2003), Argôlo (2004), Campbell \& Lamar (2004), Marques et al. (2005), Santos-Jr. (2005), Yuki \& Lema (2005), Fernandes (2006) e Curcio (2008). Informações sobre distribuição e história natural de cada espécie foram tomadas de dados de literatura e observações pessoais realizadas em Viçosa.

\section{Considerações taxonômicas}

Recentemente a taxonomia e a sistemática das serpentes neotropicais foram revisadas por meio da análise combinada de caracteres morfológicos e moleculares. Zaher et al. (2009) propuseram o desmembramento da família Colubridae, e no Brasil os antigos "colubrídeos" pertencem agora às famílias Colubridae e Dipsadidae, diferenciadas morfologicamente pela anatomia hemipeniana (Zaher et al. 2009).

Preferimos, quando possível, identificar os táxons do presente trabalho até o nível subespecífico, uma vez que estudos de revisão podem sugerir a elevação de algumas subespécies a espécies plenas no futuro.

Algumas considerações taxonômicas consideradas relevantes são dadas abaixo.

Bothrops jararaca: Fenwick et al. (2009) sugerem a inclusão de Bothrops jararaca (Wied-Neuwied, 1824) em um novo gênero, Bothropoides. A filogenia proposta por Fenwick et al. (2009) assemelha-se muito à de Wüster et al. (2002) (que mantiveram Bothrops como um único grande gênero). Neste caso, preferimos manter a nomenclatura tradicional, sustentada por Wüster et al. (2002), até que novos trabalhos comprovem uma necessidade real do desmembramento de Bothrops.

Chironius quadricarinatus: Dixon et al. (1993) reconhecem as subespécies C.q.quadricarinatus (Boie, 1827) e C.q. maculoventris Dixon, Wiest \& Chei, 1993 (esta última não ocorrendo no Brasil). Há poucos anos, Hollis (2006) reconheceu ambos os táxons como espécies plenas, decisão adotada por nós no presente trabalho.

Crotalus durissus: Segundo Wüster et al. (2005), o padrão filogeográfico pouco definido de C. durissus ao Sul da Amazônia sugere que distinções subespecíficas são injustificadas, e que $C$. $d$. terrificus (Laurenti, 1768), C. d. cascavella Wagler, 1824 e $C . d$. collilineatus Amaral, 1926 são sinônimos.

Recentemente, Hoser (2009) revalidou o gênero Caudisona Laurenti 1768, alocando C. durissus Linnaeus, 1758 e outras cascavéis. Porém, Zaher et al. (2009) apontam deficiências e afirmam que alguns arranjos taxonômicos de Hoser (2009) são equivocados. Assim, enquanto uma nova filogenia não estiver disponível, preferimos não adotar as propostas de Hoser (2009).

Erythrolamprus e Liophis: Novas filogenias indicam que o gênero Liophis Wagler, 1830 é parafilético com relação a Umbrivaga Roze, 1964 e Erythrolamprus Boie, 1826 (Zaher et al. 2009, Vidal et al. 2010). Zaher et al. (2009) sinonimizaram Erythrolamprus com Liophis, mas Curcio et al. (2009) indicaram que tal alteração era nomenclaturalmente inválida. Todavia, ainda é possível que novas propostas taxonômicas alterem no futuro o nome genérico das espécies aqui apresentadas como Liophis (e.g. transferindo-as para Erythrolamprus).

Liophis miliaris: Com base nas diagnoses fornecidas por Dixon (1983), as subespécies L. m. merremii (Wied, 1821) e L. m. orinus (Griffin, 1916) ocorrem em Viçosa. Porém, quando se analisa exemplares de toda a distribuição destes dois táxons, a diferenciação entre eles se torna confusa (A. C. Lima, com. pess.). Um estudo de revisão de L. miliaris está em andamento (A. C. Lima, com. pess.), e enquanto o status de suas subespécies permanece indefinido, preferimos não distingui-las no presente trabalho.

Liophis poecilogyrus: Duas subespécies de L. poecilogyrus foram identificadas em Viçosa: L. p. poecilogyrus (Wied, 1825) e L. p. schotti (Schlegel, 1837). Diferentemente de L. miliaris, as subespécies de L. poecilogyrus foram aqui contabilizadas como espécies distintas, com base na tese de Fernandes (2006).

Mastigodryas bifossatus: Ao contrário de Peters \& Orejas-Miranda (1970), Vanzolini (1986) sugere que não devem ser reconhecidas subespécies em M. bifossatus. Tal proposta foi corroborada pela análise de exemplares feita por Outeiral \& Lema (2003), e é seguida no presente trabalho.

Philodryas olfersii: Em sua tese de doutorado Thomas (1976) sugere a distinção de três subespécies em $P$. olfersii, diferenciadas pelo padrão de coloração e distribuição: P. o. olfersii (Lichenstein, 1823), 
P. o. herbeus (Wied-Neuwied, 1825) e P. o. latirostris Cope, 1862. Porém, o trabalho de Thomas (1976) nunca foi publicado, e diversos autores simplesmente seguiram suas propostas, validando-as sem oferecerem explicações satisfatórias que suportassem tais mudanças (Zaher et al. 2008). Assim, seguimos aqui a proposta de Zaher et al. (2008) e não reconhecemos subespécies para $P$. olfersii.

Spilotes pullatus: Peters \& Orejas-Miranda (1970) reconhecem cinco subespécies, das quais três ocorrem no Brasil: $S$. $p$. pullatus (Linnaeus, 1758), S. p. anomalepis Bocourt, 1888 e S. p. maculatus Amaral, 1929. Para Savage (2002), a variação individual extrema e complicada torna suspeita as tentativas de reconhecer raças geográficas em $S$. pullatus. Na América Central, por exemplo, as supostas variações geográficas no padrão de coloração apresentamse como variações individuais (Savage 2002). Achamos então mais conveniente não utilizar nomenclatura subespecífica para os exemplares de $S$. pullatus de Viçosa.

Taeniophallus e Echinanthera: A taxonomia destes dois gêneros vem sendo motivo de debates desde que Di-Bernardo (1992) revalidou Echinanthera Cope 1894 (Di-Bernardo 1992, Myers 1974, Myers \& Cadle 1994). Schargel et al. (2005) mantiveram Echinanthera e Taeniophallus como válidos, sendo o último dividido em três "grupos", podendo se tratar de um gênero parafilético. É possível, portanto, que as espécies incluídas em Taniophallus em nosso estudo (T. affinis e $T$. occipitalis) sejam realocadas em um novo gênero futuramente.

Taeniophallus occipitalis: Trata-se de um complexo de espécies recentemente revisado, cujos resultados ainda se encontram em fase de publicação (e.g. Santos-Jr. et al. 2008). Com base em dados não publicados (Santos-Jr 2005), o nome Taeniophallus miolepis (Boettger, 1891) poderá ser aplicado aos exemplares de Viçosa no futuro, no lugar de Taeniophallus occipitalis (Jan, 1863).

Xenodon merremii e X. nattereri: Zaher et al. (2009) sugerem que os gêneros Waglerophis Romano \& Hoge, 1972 e Lystrophis Cope, 1885 são sinônimos júniores de Xenodon Boie, 1826, baseando-se em informações morfológicas e moleculares. Neste trabalho, seguimos a proposta desses autores.

\section{Resultados e Discussão}

\section{Espécies com registro confirmado no Município de Viçosa}

Foram confirmadas 34 espécies de serpentes para o Município de Viçosa, o equivalente a 24,4\% da fauna de ofídios conhecida para Minas Gerais (Bérnils et al. 2009) e 25,3\% do total conhecido para a Mata Atlântica (Rodrigues 2005). Se comparada a outras localidades da Mata Atlântica (e áreas de transição com Cerrado) do Sudeste do Brasil onde já foram realizados levantamentos de serpentes (excetuando-se aqueles muito preliminares), podemos observar que Viçosa possui uma das ofidiofaunas mais ricas já registradas (Tabela 1). Interessante ressaltar que as áreas com mais registros de espécies na Tabela 1 (Marques \& Sazima 2004, Levandeira-Gonçalves et al. 2007, Barros-Filho 2008, Condez et al. 2009, Marques et al. 2009b, São-Pedro \& Pires 2009, e o presente estudo), coletaram informações de espécimes depositados em coleções científicas, o que reforça a importância das mesmas como valiosos bancos de dados sobre determinada região geográfica (Prudente 2003).

Dipsadidae é a família de serpentes mais diversa em Viçosa (21 espécies), seguida por Colubridae (6), Elapidae (3), Viperidae (2), Anomalepididae (1) e Boidae (1). Foram analisados 544 exemplares, a maioria (521) depositada no MZUFV, seguido do IBSP (22) e FUNED (1). A coleção do MZUSP não possui nenhuma serpente procedente de Viçosa ou municípios vizinhos (C. Castro-Mello, com. pess.). O baixo número de espécimes procedentes de Viçosa depositados no IBSP e a ausência de material no MZUSP, duas das maiores coleções de serpentes da América Latina, reafirma o valor do MZUFV como coleção de caráter regional (Prudente 2003, Costa et al. 2009a). Abaixo, apresentamos uma lista comentada das espécies registradas no Município de Viçosa. Quando existentes, são fornecidas informações sobre o tipo de ambiente em que os exemplares foram coletados, além de observações pessoais dos autores e outros pesquisadores da região.

Tabela 1. Número de espécies de serpentes registradas em algumas localidades da Mata Atlântica (e áreas de transição deste bioma com o Cerrado) do Sudeste do Brasil.

Table 1. Number of snake species recorded in some localities in the Atlantic Forest (and transitional areas between this biome and the Cerrado) in Southeastern Brazil.

\begin{tabular}{lccc}
\hline \multicolumn{1}{c}{ Localidade } & Estado & Número de espécies & Referência \\
\hline Município de São Paulo & SP & 68 & Marques et al. (2009b) \\
Municípios integrantes do & & 56 & Levandeira-Gonçalves et al. (2007), \\
Parque Nacional da Serra dos Órgãos & RJ & 46 & Barros-Filho (2008) \\
Municípios de Tapiraí e Piedade & SP & 34 & Este trabalho \\
Município de Viçosa & MG & 32 & Marques \& Sazima (2004) \\
Estação Ecológica Juréia-Itatins e arredores & SP & 28 & São-Pedro \& Pires (2009) \\
Ouro Branco & MG & 27 & Hartmann et al. (2009a) \\
Parque Estadual da Serra do Mar, Núcleo Santa Virgínia & SP & 27 & Centeno et al. (2008) \\
São Sebastião, São Paulo & SP & 27 & Pontes \& Rocha (2008) \\
Serra do Medanha & RJ & 24 & Hartmann et al. (2009b) \\
Parque Estadual da Serra do Mar, Núcleo Picinguaba & SP & 22 & Bertoluci et al. (2009) \\
Estação Ambiental de Peti & MG & Salles et al. (2010) \\
Parque Natural Municipal da Taquara & RJ & 21 & Centeno et al. (2008) \\
Ilhabela & SP & 20 & Sazima (2001) \\
Parque Estadual Intervales & SP & 19 & Sazima \& Haddad (1992) \\
Serra do Japi & SP & 13 & \\
\hline
\end{tabular}




\section{FAMÍLIA ANOMALEPIDIDAE}

Liotyphlops wilderi (Garman, 1883). N = 5 (Figura 2a).

Serpente áglifa e de hábito fossorial, praticamente nada se conhece sobre a biologia desta espécie, que ocorre em áreas de Cerrado e Mata Atlântica do Sudeste do Brasil (Dixon \& Kofron 1983). Contudo, sabe-se que a alimentação das serpentes Scolecophidia é baseada em invertebrados (Greene 1997). Há registros de cupins, além de larvas e pupas de formigas na dieta de algumas espécies de Liotyphlops (França et al. 2008, Parpinelli 2008). Outra espécie congenérica, L. beui, possui atividade marcadamente sazonal, sendo raramente encontrada durante a estação seca (Parpinelli \& Marques 2008). Os três espécimes de L. wilderi de Viçosa para os quais possuímos informação sobre hábitat foram coletados no campus da UFV, indicando que a espécie sobrevive em ambientes alterados. Em outras localidades o gênero Liotyphlops também tem sido encontrado eventualmente em áreas antrópicas, associado a jardins urbanos e pastagens (Marques et al. 2009b; DLP obs. pess.). É possível, portanto que haja algum nível de adaptação dessas serpentes subterrâneas aos ambientes alterados.

\section{FAMÍLIA BOIDAE}

Corallus hortulanus (Linnaeus, 1758). N = 1 (Figura 2b).

Arborícola (forrageando ocasionalmente no solo) e com atividade noturna (Cunha \& Nascimento 1978, Martins \& Oliveira 1998, Marques \& Sazima 2004), distribui-se na Amazônia, Cerrado, Caatinga e Mata Atlântica (Henderson 1997), habitando florestas e áreas alteradas (Cunha \& Nascimento 1978, Martins \& Oliveira 1998, Argôlo 2004). Corallus hortulanus tem dentição áglifa e dieta generalista, alimentando-se de diversos grupos de vertebrados (Cunha \& Nascimento 1978, Martins \& Oliveira 1998, Marques \& Sazima 2004). Vivípara, pode dar à luz entre três e 24 filhotes, que nascem na estação chuvosa (Pizzatto \& Marques 2007). Não há informações sobre o tipo de ambiente onde o único exemplar registrado neste estudo se encontrava.

\section{FAMÍLIA COLUBRIDAE}

\section{Chironius bicarinatus (Wied, 1820). N = 6 (Figura 2c).}

Semiarborícola e diurna (Dixon et al. 1993), é endêmica da Mata Atlântica, ocorrendo em florestas e áreas alteradas (Dixon et al. 1993, Sazima \& Haddad 1992, Argôlo 2004, Marques \& Sazima 2004). Tem dentição áglifa e alimenta-se principalmente de anuros (Dixon et al. 1993). É ovípara, com ciclo reprodutivo sazonal, sendo que o recrutamento (nascimento) de juvenis ocorre principalmente no fim da estação chuvosa (Marques et al. 2009a) e o tamanho das ninhadas varia de quatro a 14 ovos (Dixon et al. 1993, Marques et al. 2009a). Machos podem realizar combates rituais (Almeida-Santos \& Marques 2002, Marques et al. 2009a). Fêmeas estocam o esperma dos machos até o período de fertilização (Marques et al. 2009a). Não há informação sobre o ambiente onde os espécimes deste trabalho foram coletados.

Chironius exoletus (Linnaeus, 1758). N = 10 (Figura 2d).

Semiarborícola e diurna (Dixon et al. 1993), possui ampla distribuição, com registros na Amazônia, Mata Atlântica (Dixon et al. 1993), Pantanal (Kawashita-Ribeiro, 2007) e Cerrado (França et al. 2008). Habita florestas e áreas abertas (Dixon et al. 1993, Argôlo 2004) é áglifa e possui dieta generalista, embora anuros sejam suas presas principais (Dixon et al. 1993, França et al. 2008). É ovípara, e a análise de espécimes da Mata Atlântica indica a presença de reprodução sazonal, com recrutamento na segunda metade da estação chuvosa (Marques 1998). O tamanho da ninhada varia de quatro a 12 ovos (Dixon et al. 1998, Marques 1998). Dos 10 espécimes registrados em Viçosa, temos informações sobre dois, ambos coletados no campus da UFV.

Chironius quadricarinatus (Boie, 1827). N = 10 (Figura 2e).

Semiarborícola e diurna (Dixon et al. 1993), ocorre principalmente no Cerrado, tanto em áreas abertas quanto florestais (Dixon et al. 1993), havendo também registros na Mata Atlântica (Argôlo 2004, Condez et al. 2009) e savanas amazônicas (França et al. 2006). Tem dentição áglifa e alimentase de pequenos vertebrados (França et al. 2008), embora em algumas regiões sua dieta pareça se restringir a anuros (Dixon et al. 1993, Pinto et al. 2008). Ovípara, suas ninhadas variam de três a nove ovos, e a reprodução parece ser contínua (Pinto 2006). Um indivíduo foi coletado no campus da UFV.

\section{Mastigodryas bifossatus (Raddi, 1820). N = 10 (Figura 2f).}

Possui hábitos terrícolas e diurnos (Marques \& Muriel 2007), tem distribuição ampla na América do Sul (Peters \& OrejasMiranda 1970), principalmente em áreas abertas no Cerrado e Pantanal, ocorrendo em baixas densidades na Amazônia e Mata Atlântica (Marques \& Muriel 2007). Tem dentição áglifa e alimenta-se de uma variedade de vertebrados, incluindo anfisbenídeos e outras serpentes (Marques et al. 2005, França et al. 2008), mas anfíbios e mamíferos têm sido as principais presas reportadas (Cunha \& Nascimento 1978, Marques \& Muriel 2007). É ovípara (quatro a 24 ovos), e a análise de populações do Sudeste da América do Sul indica a presença de reprodução contínua, mas com pico de nascimentos no fim da estação chuvosa e início da estação seca (Marques \& Muriel 2007). Embora não haja informações sobre o tipo de ambiente utilizado pelos espécimes depositados na coleção do MZUFV, no passado, M. bifossatus era comum em áreas de várzea na cidade de Viçosa e no campus da UFV (JLP, obs. pess.).

Simophis rhinostoma (Schlegel, 1837). N = 10 (Figura 2g).

Terrícola e diurna (Sazima \& Abe 1991), ocorre em bordas de matas e áreas abertas (incluindo ambientes alterados) do Brasil Central ao Sul, no Nordeste (Sazima \& Abe 1991, Jordão \& Bizerra 1996, Argôlo 1998), e no Paraguai (Cacciali et al. 2009). Possui dentição áglifa e alimenta-se de anuros, principalmente do gênero Physalaemus (Bizerra et al. 1994). Ovípara, suas ninhadas variam entre dois e sete ovos, e o período reprodutivo parece ser longo, de outubro a maio, mas com presença de dois picos, em outubro-novembro e abril (Jordão \& Bizerra 1996). Seis exemplares de Viçosa são provenientes do campus da UFV e de áreas urbanizadas.

Spilotes pullatus (Linnaeus, 1758). N = 3 (Figura 2h).

Serpente semiarborícola e diurna (Sazima \& Haddad 1992, Marques \& Sazima 2004), possui ampla distribuição pela América do Sul, ocorrendo em florestas e em ambientes alterados, aos quais parece ser bem adaptada (Cunha \& Nascimento 1978, Argôlo 2004). Possui dentição áglifa e sua dieta é constituída por diversos vertebrados, principalmente roedores (Cunha \& Nascimento, Marques \& Sazima 2004). É ovípara, e a reprodução na Mata Atlântica parece ser sazonal, com ninhadas de cinco a 12 ovos e recrutamento no final da estação chuvosa (Marques \& Sazima 2004, Hauzman et al. 2005). Em Viçosa, todos os indivíduos foram coletados em atividade, durante o dia, em ambiente urbano. 

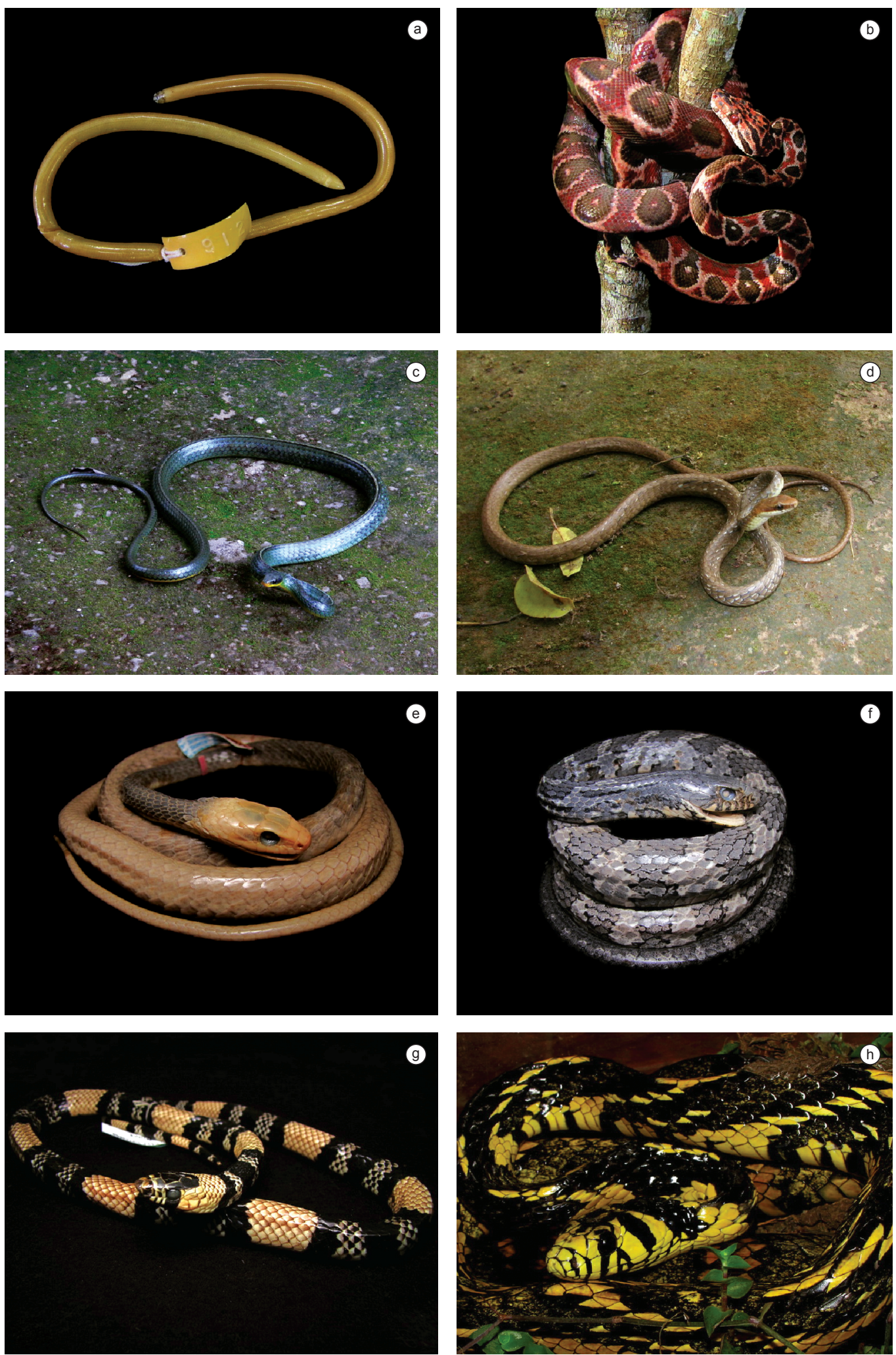

Figura 2. Espécies de serpentes com registro confirmado em Viçosa (quando disponível, preferiu-se ilustrar as pranchas com fotografias de espécimes vivos procedentes de localidades próximas de Viçosa ao invés de material preservado). a) Liotyphlops wilderi (MZUFV 912); b) Corallus hortulanus (Guiricema, $25 \mathrm{~km}$ Sudeste de Viçosa); c) Chironius bicarinatus (Ervália, $25 \mathrm{~km}$ Leste de Viçosa); d) Chironius exoletus (Araponga, $35 \mathrm{~km}$ Leste de Viçosa); e) Chironius quadricarinatus (MZUFV 53); f) Mastigodryas bifossatus (MZUFV 100); g) Simophis rhinostoma (MZUFV 1305); h) Spilotes pullatus. Fotos: H. C. Costa, exceto C, de D. J. Santana.

Figure 2. Snake species with confirmed register in Viçosa (when available, pictures of live specimens from localities close to Viçosa were preferred to illustrate plates instead of using preserved material). a) Liotyphlops wilderi (MZUFV 912); b) Corallus hortulanus (Guiricema, $25 \mathrm{~km}$ Southeast from Viçosa); c) Chironius bicarinatus (Ervália, $25 \mathrm{~km}$ East from Viçosa); d) Chironius exoletus (Araponga, $35 \mathrm{~km}$ East from Viçosa); e) Chironius quadricarinatus (MZUFV 53); f) Mastigodryas bifossatus (MZUFV 100); g) Simophis rhinostoma (MZUFV 1305); h) Spilotes pullatus. Photos: H. C. Costa, except C, by D. J. Santana. 


\section{FAMÍLIA DIPSADIDAE}

Elapomorphus quinquelineatus (Raddi, 1820). N = 26 (Figura 3a).

Espécie fossorial e endêmica da Mata Atlântica do Sudeste do Brasil (Pontes \& Rocha 2008). Embora Marques et al. (2001) e Pontes \& Rocha (2008) considerem-na diurna, Cardoso et al. (2001) citam hábitos noturnos para a espécie. Em Viçosa, recebemos doações de exemplares encontrados em atividade e coletados durante o dia. Contudo, já observamos um indivíduo em atividade noturna no campus da UFV. Assim, consideramos que E. quinquelineatus pode apresentar tanto atividade diurna quanto noturna. Tem dentição opistóglifa e dieta constituída por vertebrados e invertebrados (Cardoso et al. 2001, Marques et al. 2001, Pontes \& Rocha 2008). A análise do conteúdo estomacal de espécimes do MZUFV indicou a presença de anfisbenídeos (C. M. Herédias-Ribas, com. pess.). É ovípara, mas pouco se sabe sobre sua reprodução. Cardoso et al. (2001) relatam a eclosão de um ovo em março. É provável, portanto, que o recrutamento de filhotes ocorra no fim da estação chuvosa e início da seca. Bertoluci et al. (2009) afirmam que E. quinquelineatus está associada a áreas de mata, e que sua presença poderia ser um bom indicativo de qualidade do ambiente. Em Viçosa, todos os exemplares com informações sobre o tipo de hábitat $(\mathrm{N}=13)$ foram coletados em locais alterados (em chácaras, pastagens antigas em estágio inicial de regeneração, no campus da UFV e em área urbana). Mesmo que os fragmentos florestais sejam importantes para a ocorrência de E. quinquelineatus em Viçosa, os dados acima apontam que a espécie possui certa resistência às alterações antrópicas, não parecendo ser um bom indicador de qualidade ambiental.

Erythrolamprus aesculapii venustissimus (Wied-Neuwied, 1821). $\mathrm{N}=33$ (Figura 3b).

Terrícola e diurna (Sazima \& Abe 1991, Sazima \& Haddad 1992, Marques \& Sazima 2004), distribui-se na Mata Atlântica do Nordeste ao Sul do Brasil, e em alguns ambientes de transição (Curcio 2008). Tem dentição opistóglifa, é ofiófaga, mas os juvenis também podem se alimentar de lagartos Gymnophthalmidae e anfíbios Gymnophiona (Sazima \& Abe 1991, Marques \& Puorto 1994). Ovípara, coloca de um a oito ovos e apresenta reprodução contínua ao longo de todo o ano (Marques 1996a). O padrão cromático de E. aesculapii é considerado mimético de Micrurus (Marques \& Puorto 1991). Populações simpátridas com Micrurus frontalis e M. lemniscatus (espécies que possuem coloração coral em tríades) apresentam padrão cromático com díades bem definidas, enquanto que populações simpátridas com M. corallinus (que possui mônades) tendem a apresentar fusão das díades (Marques \& Puorto 1991). Em Viçosa, há indivíduos de E. a. venustissimus com díades completas $(\mathrm{n}=26)$ e parcialmente fundidas $(n=7)$. A ocorrência de ambos os padrões cromáticos pode estar relacionada à presença no município das três espécies de Micrurus supracitadas, e a maior proporção de indivíduos de E. a. venustissimus com díades completas pode ter ligação com a possível menor densidade de $M$. corallinus em relação a $M$. frontalis. Nove espécimes possuem dados sobre o ambiente de coleta, tendo sido encontrados em áreas alteradas (campus da UFV, fazendas e área urbana). Contudo, tivemos acesso a registros fotográficos desta espécie em um fragmento de mata secundária.

Helicops sp. $\mathrm{N}=1$ (Figura 3c).

O único indivíduo de Helicops registrado foi coletado em área urbana e possui características intermediárias entre H. carinicaudus (Wied-Neuwied, 1825) e H. infrataeniatus (Jan,
1865) propostas por Yuki \& Lema (2005). Como sua identidade ainda não pôde ser determinada, utilizamos neste trabalho o nome Helicops sp. As espécies de Helicops são aquáticas, com atividade diurna e noturna, dentição áglifa, se alimentam principalmente de peixes e anuros, e são ovíparas ou vivíparas (Marques et al. 2001, Marques \& Sazima 2004, Marques et al. 2005).

Liophis miliaris (Linnaeus, 1758). N = 28 (Figura 3d).

Semiaquática, com atividade diurna e noturna (Sazima \& Haddad 1992, Marques \& Sazima 2004), possui ampla distribuição na América do Sul (Dixon 1989), habitando matas e áreas abertas (Argôlo 2004, Marques \& Sazima 2004). Possui um histórico taxonômico complexo (Dixon 1983), com populações de diferentes regiões podendo representar espécies distintas (veja Giraudo et al. 2006). Uma nova revisão taxonômica encontra-se em andamento (A. C. Lima, com. pess.). Tem dentição áglifa e sua dieta consiste principalmente em anuros e peixes (Sazima \& Haddad 1992, Pizzatto 2003, Marques \& Sazima 2004), embora aprese também anfíbios Gymnophiona, lagartos e outras serpentes (Michaud \& Dixon 1989, Machado et al. 1998, Marques \& Sazima 2004, Bonfiglio \& Lema 2006, Braz et al. 2006). É ovípara, com ninhadas entre um e 30 ovos (Pizzatto 2003, Pizzatto \& Marques 2006). Na região Sudeste do Brasil a reprodução parece ser sazonal, concentrada no final do ano, com recrutamento nos primeiros meses do ano seguinte (Marques 1998, Pizzatto 2003, Pizzatto \& Marques 2006). Há também registro de estoque de esperma por parte das fêmeas (Pizzatto 2003). Dois exemplares examinados foram coletados no campus da UFV, e um foi capturado no interior de floresta secundária, não havendo informações sobre os demais. Contudo, há ainda diversos registros de indivíduos não coletados, em áreas alagadas em bordas de mata secundária (Mata da Biologia e Mata do Paraíso), avistados forrageando e apresando os anuros Hypsiboas faber e Physalaemus feioi à noite (E. T. da Silva, J. S. Dayrell, J. V. Lacerda e J. Tolledo, com. pess.).

Liophis poecilogyrus poecilogyrus (Wied, 1825). N = 26 (Figura 3e).

Serpente terrícola, com atividade diurna e noturna (Marques et al. 2001, Pontes \& Rocha 2008), distribuição na Mata Atlântica brasileira, do Sul do Estado da Bahia ao longo do Sudeste (Fernandes 2006), habitando áreas antrópicas e florestas (Pontes \& Rocha 2008). Possui dentição áglifa e alimenta-se principalmente de anfíbios (Pinto \& Fernandes 2004), mas também apresa anfisbênios, lagartos e peixes (Michaud \& Dixon 1989). Tem reprodução não-sazonal, com múltiplas ninhadas (seis a 15 ovos) ao ano (Pinto \& Fernandes 2004). O único exemplar deste estudo com informações sobre ambiente de coleta, foi capturado no campus da UFV.

Liophis poecilogyrus schotti (Schlegel, 1837). N = 2 (Figura 3f).

Terrícola e com atividade diurna e noturna (Marques et al. 2005; Sawaya et al. 2008). Tem ampla distribuição, ocorrendo nas Guianas, Suriname e Venezuela, no Centro-Norte e Nordeste, e do Sudeste ao Sul do Brasil (Cerrado e Mata Atlântica), além do Paraguai e Argentina (Fernandes 2006). Habita bordas de matas, campos e áreas antrópicas (Sawaya et al. 2008). Tem dentição áglifa e sua dieta constitui-se de anuros e lagartos (Michaud \& Dixon 1989, Marques et al. 2005, Sawaya et al. 2008). Dados de espécimes do Nordeste do Brasil indicam reprodução não-sazonal, com múltiplas ninhadas (três a 17 ovos) ao longo do ano (Vitt \& Vangilder 1983, Pizzatto et al. 2008a). Não há informação sobre o ambiente onde os espécimes de Viçosa foram coletados. 

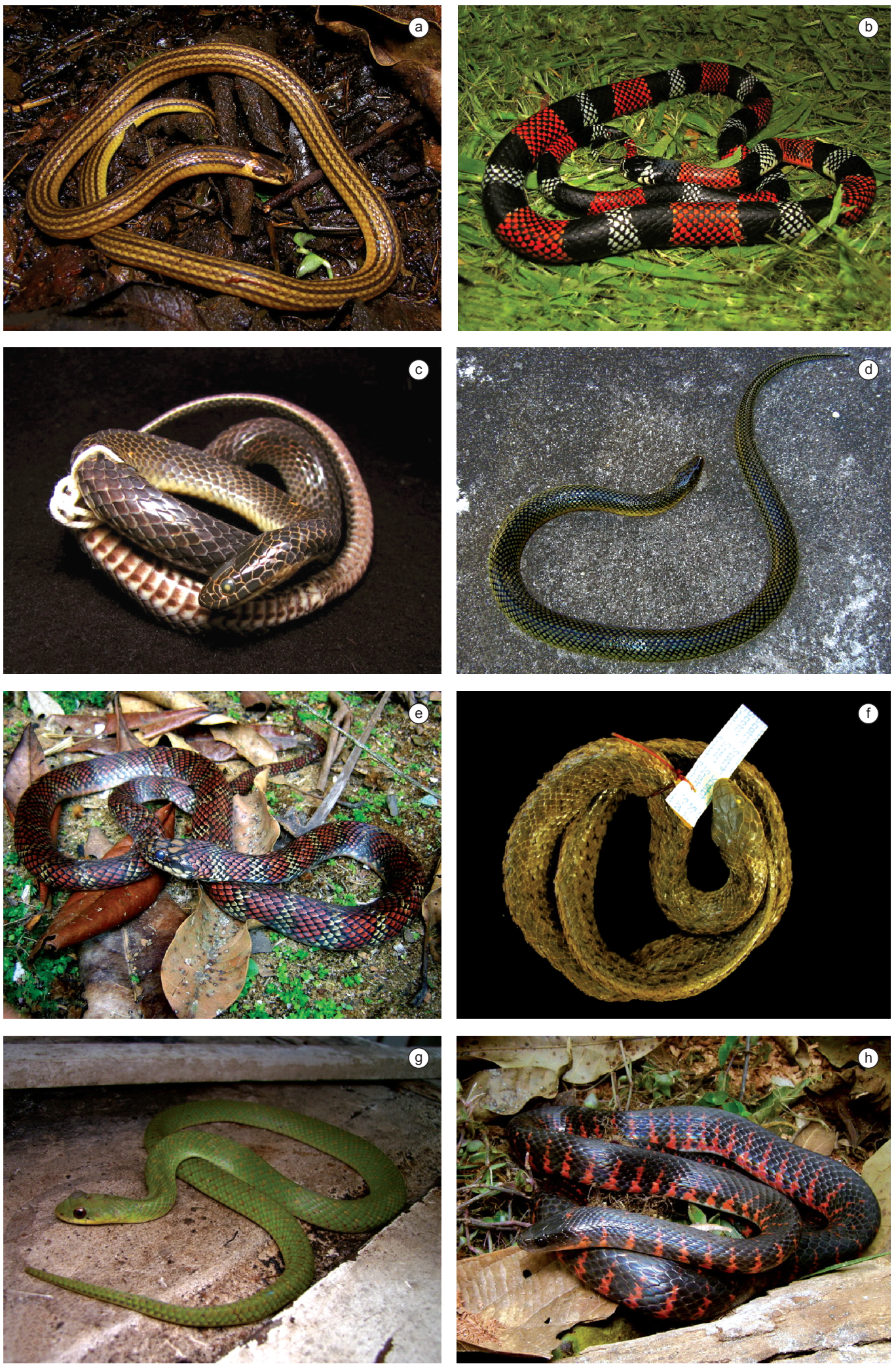

Figura 3. Espécies de serpentes com registro confirmado em Viçosa (quando disponível, preferiu-se ilustrar as pranchas com fotografias de espécimes vivos procedentes de localidades próximas de Viçosa ao invés de material de preservado). a) Elapomorphus quinquelineatus; b) Erythrolamprus aesculapii venustissimus; c) Helicops sp. (MZUFV 960); d) Liophis miliaris; e) Liophis poecilogyrus poecilogyrus (Muriaé, $55 \mathrm{~km}$ Sudeste de Viçosa); f) Liophis poecilogyrus schotti (MZUFV 178); g) Liophis typhlus brachyurus; h) Oxyrhopus clathratus (Araponga, 35 km Leste de Viçosa). Fotos: H. C. Costa.

Figure 3. Snake species with confirmed register in Viçosa (when available, pictures of live specimens from localities close to Viçosa were preferred to illustrate plates instead of using preserved material). a) Elapomorphus quinquelineatus; b) Erythrolamprus aesculapii venustissimus; c) Helicops sp. (MZUFV 960); d) Liophis miliaris; e) Liophis poecilogyrus poecilogyrus (Muriaé, $55 \mathrm{~km}$ Southeast from Viçosa); f) Liophis poecilogyrus schotti (MZUFV 178); g) Liophis typhlus brachyurus; h) Oxyrhopus clathratus (Araponga, $35 \mathrm{~km}$ East from Viçosa). Photos: H. C. Costa. 
Liophis typhlus brachyurus (Cope, 1887). $\mathrm{N}=7$ (Figura 3g).

Terrícola, com atividade diurna e noturna (Marques et al. 2001). Ocorre na Mata Atlântica, Cerrado e Caatinga do Sudeste, Centro-Oeste e Nordeste do Brasil (Silva 2007), sendo apta a habitar ambientes antrópicos (Martins \& Oliveira 1998, Marques et al. 2009b). É áglifa e alimenta-se de anuros (Marques et al. 2001). Possui reprodução não sazonal, com múltiplas ninhadas no ano (Pizzatto et al. 2008a). Martins \& Oliveira (1998) indicam ninhadas de dois a cinco ovos para L. t. typhlus (Linnaeus, 1758) na Amazônia. Quatro dos exemplares de Viçosa foram coletados no campus da UFV, e um em floresta secundária.

Oxyrhopus clathratus Duméril, Bibron \& Duméril, 1854. $\mathrm{N}=11$ (Figura 3h).

Possui hábito terrícola e atividade noturna (Sazima 2001, Marques \& Sazima 2004). Endêmica da Mata Atlântica (Sazima 2001), distribui-se do Nordeste ao Sul do Brasil, da Bahia ao Rio Grande do Sul, ocorrendo também em Missiones, Argentina (Peters \& Orejas-Miranda 1970, Argôlo 2001). Habita florestas e ambientes antropizados (Morato 2005, Marques et al. 2009b), tem dentição opistóglifa e apresenta mudança ontogenética na dieta, com jovens apresando lagartos, enquanto os adultos se alimentam principalmente de roedores (Sazima 2001, Marques \& Sazima 2004). É ovípara e apresenta reprodução sazonal (Marques 1998). Marques (1998) cita duas ninhadas, com nove e 13 ovos e sugere que a eclosão deve ocorrer na segunda metade da estação chuvosa. No presente trabalho, registramos quatro recém-nascidos e três ovos em estágio final de desenvolvimento (MZUFV 709, todos do mesmo local, e provavelmente da mesma ninhada), coletados no fim de fevereiro de 1991 no campus da UFV. Estes dados corroboram Marques (1998) quanto à época de recrutamento de juvenis, e amplia a variação no tamanho da ninhada de O. clathratus para sete a 13 ovos. Nove exemplares deste estudo foram coletados em áreas altamente modificadas (campus da UFV e chácaras), e um em área de floresta secundária. Além disso, em duas oportunidades já observamos indivíduos dessa espécie na área urbana da cidade, próximo à entrada do campus da UFV.

Oxyrhopus guibei Hoge \& Romano, 1978. N = 5 (Figura 4a).

Serpente terrícola, predominantemente crepuscular e noturna, que também pode estar ativa durante o dia (Sazima \& Abe 1991, Sazima \& Haddad 1992, Sawaya et al. 2008). Distribuise pelo Sul, Sudeste, Centro-oeste e Nordeste do Brasil, na Argentina, Paraguai e Bolívia (Zaher \& Caramaschi 1992, Freire 1999), ocorrendo em bordas de matas, áreas abertas naturais e antropizadas (Sazima \& Abe 1991, Sawaya et al. 2008). Sua presença na Mata Atlântica pode ser considerada uma invasão (Marques et al. 2001). Tem dentição opistóglifa, e enquanto os jovens se alimentam de lagartos, os adultos apresam roedores (Andrade \& Silvano 1996). A preferência por áreas abertas e a dieta composta principalmente por animais que vivem em ambientes urbanos indicam que $O$. guibei é uma espécie potencialmente adaptada a locais com alteração antrópica (Andrade \& Silvano 1996). No Município de São Paulo, por exemplo, é a espécie mais coletada pela população, recebida no Instituto Butantan (Barbo 2008, Marques et al. 2009b). Ovípara, suas ninhadas têm três a 20 ovos, e as fêmeas são capazes de estocar esperma dos machos (Pizzatto \& Marques 2002). Embora tenha reprodução contínua, mais fêmeas estão aptas à cópula no fim da estação seca e o recrutamento dos filhotes ocorre principalmente no final da estação chuvosa (Pizzatto \& Marques 2002). Há informações sobre o local de coleta de três espécimes de Viçosa, todos de área urbana na periferia da cidade.
Oxyrhopus petola digitalis (Reuss, 1834). $\mathrm{N}=13$ (Figura 4b).

Possui hábito terrícola e atividade noturna (Marques et al. 2001). Bartlett, R.D. \& Bartlett, P. (2003) indicam que na Amazônia $O$. petola ocasionalmente é encontrada ativa durante o dia, e pode apresentar hábitos arborícolas. Amplamente distribuída, ocorre do Panamá ao longo da América do Sul, até o Brasil (Peters \& Orejas-Miranda 1970), habitando tanto florestas quanto ambientes alterados (Cunha \& Nascimento 1978, Bartlett, R.D. \& Bartlett, P. 2003, Argôlo 2004). Opistóglifa, sua dieta inclui roedores, lagartos e aves (Cunha \& Nascimento 1978, Bernarde \& Machado 2000, Marques et al. 2001, Palmuti et al. 2009), e sua biologia reprodutiva é praticamente desconhecida. Sabe-se que é ovípara, com ninhadas variando entre três e 10 ovos (Marques et al. 2001, Bartlett, R.D. \& Bartlett, P. 2003). Sete espécimes de Viçosa foram coletados no campus da UFV e em área urbana.

Oxyrhopus rhombifer rhombifer Duméril, Bibron \& Duméril, 1854. $\mathrm{N}=1$ (Figura 4c).

Espécie terrícola e noturna (Sawaya et al. 2008), ocorrendo da Argentina a Minas Gerais e Rio de Janeiro, no Brasil (Peters \& Orejas-Miranda 1970), em áreas abertas como campos e bordas de matas (Sawaya et al. 2008). Tem dentição opistóglifa e dieta variada (Maschio et al. 2004), mas roedores e lagartos parecem ser suas presas principais (Sawaya et al. 2008). É ovípara, mas informações detalhadas sobre sua reprodução não estão disponíveis (Sawaya et al. 2008). O único exemplar deste estudo foi encontrado em condomínio residencial na área urbana, margeado por matas secundárias.

Philodryas olfersii (Lichtenstein, 1823). N = 22 (Figura 4d).

Semiarborícola e diurna (Hartmann \& Marques 2005), possui ampla distribuição na América do Sul cis-andina (Thomas 1976), habitando regiões florestadas e abertas (Argôlo 2004, Hartmann \& Marques 2005, Pontes \& Rocha 2008). Tem dentição opistóglifa e dieta variada, apresando anuros, mamíferos, aves e lagartos (Hartmann \& Marques 2005). É ovípara, com ninhadas de dois a 20 ovos (Oliveira \& Della-Lucia 1993, Fowler et al. 1998), postura e nascimento dos filhotes na estação chuvosa (Oliveira \& DellaLucia 1993, Fowler et al. 1998). Há indícios de estocagem de esperma por parte das fêmeas, porém são ainda necessários estudos para comprovação (Fowler et al. 1998). Oliveira \& Della-Lucia (1993) encontraram três ninhadas (20, 13 e 12 ovos) depositadas em ninhos da formiga Acromyrmex subterraneus subterraneus no Município de Coimbra, limítrofe a Viçosa. Dez espécimes de Viçosa foram coletados em ambientes alterados, no campus da UFV e em área urbana.

Philodryas patagoniensis (Girard, 1858). N = 9 (Figura 4e).

Terrícola (ocasionalmente forrageando na vegetação) e diurna (Hartmann \& Marques 2005), ocorre principalmente em áreas abertas (Hartmann \& Marques 2005, Sawaya et al. 2008), na Argentina, Chile, Uruguai, Paraguai, Bolívia e Brasil (Thomas 1976, Sousa \& Freire 2008). Tem dentição opistóglifa e sua dieta é variada, apresando anuros, mamíferos, aves, lagartos e serpentes (Sazima \& Haddad 1992, Hartmann \& Marques 2005). Ovípara, coloca de três a 19 ovos, e apresenta ciclo reprodutivo sazonal, no fim da estação seca e primeira metade da estação chuvosa (Fowler et al. 1998). No cativeiro, foi registrado um período de incubação de 65 dias, com nascimento dos filhotes em fevereiro (Fowler et al. 1998). Cinco espécimes possuem informações sobre o hábitat de coleta, sendo dois capturados no campus da UFV, dois na área urbana de Viçosa, e outro na Estação de Pesquisa, Treinamento e Educação Ambiental Mata do Paraíso - EPTEAMP (o qual não se sabe se proveniente do interior de mata ou de áreas abertas adjacentes). 

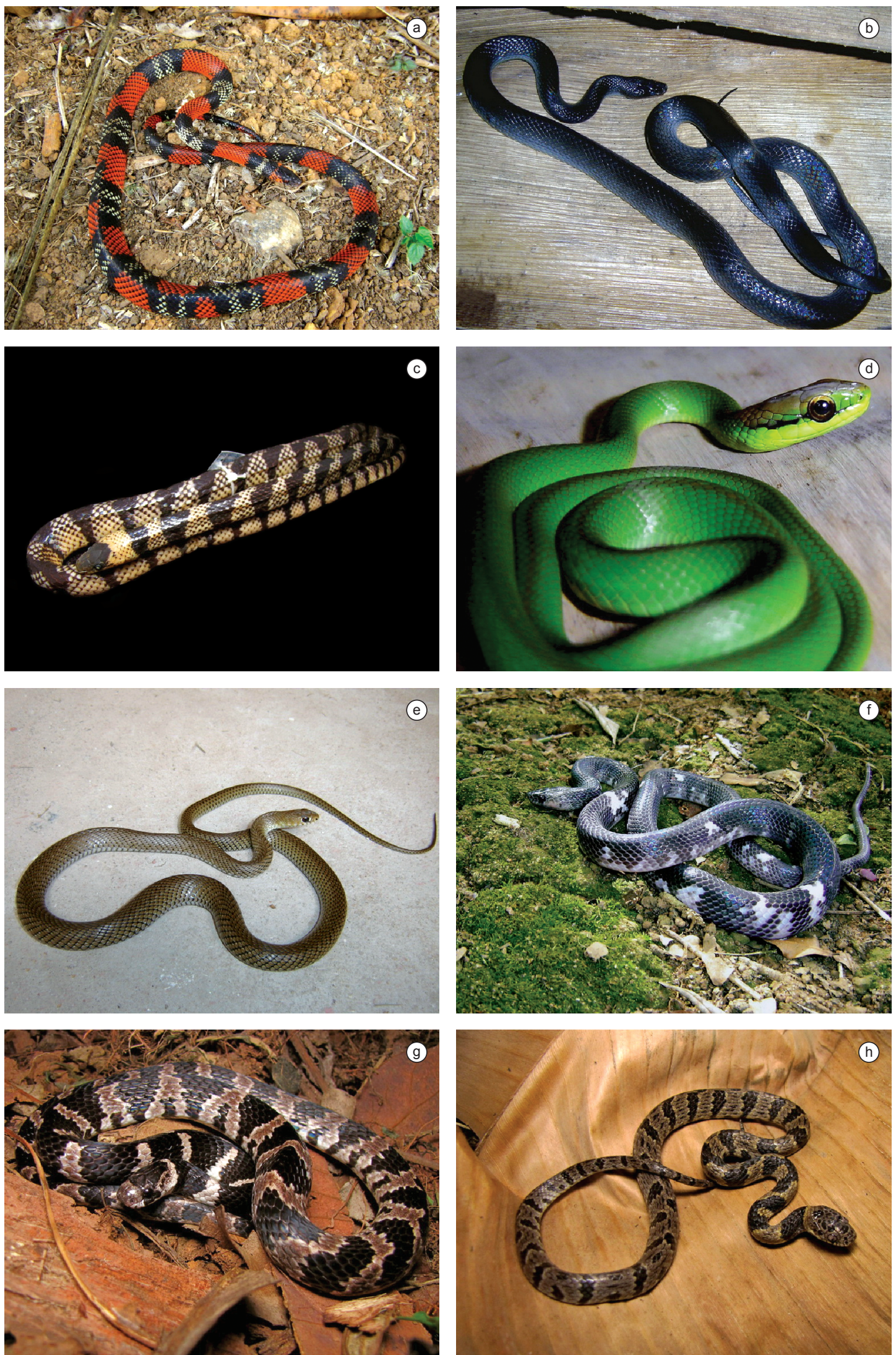

Figura 4. Espécies de serpentes com registro confirmado em Viçosa. a) Oxyrhopus guibei; b) Oxyrhopus petola digitalis; c) Oxyrhopus rhombifer rhombifer (MZUFV 714); d) Philodryas olfersii; e) Philodryas patagoniensis; f) Pseudoboa nigra; g) Sibynomorphus mikanii; h) Sibynomorphus neuwiedi. Fotos: H. C. Costa.

Figure 4. Snake species with confirmed register in Viçosa. a) Oxyrhopus guibei; b) Oxyrhopus petola digitalis; c) Oxyrhopus rhombifer rhombifer (MZUFV 714); d) Philodryas olfersii; e) Philodryas patagoniensis; f) Pseudoboa nigra; g) Sibynomorphus mikanii; h) Sibynomorphus neuwiedi. Photos: H. C. Costa. 
Pseudoboa nigra (Duméril, Bibron \& Duméril, 1854). $\mathrm{N}=1$ (Figura 4f).

Terrícola e noturna (Strüssmann \& Sazima 1993, Marques et al. 2005), ocorre do Norte e Nordeste do Brasil até a região Sudeste e Centro-oeste, além da Bolívia e Argentina (Peters \& Orejas-Miranda 1970). Habita principalmente áreas abertas, mas também ambientes florestais (Strüssmann \& Sazima 1993, Argôlo 2004). Tem dentição opistóglifa e se alimenta de lagartos e ovos (Vitt \& Vangilder 1983, Strüssmann \& Sazima 1993, Marques et al. 2005, Palmuti et al. 2009, Orofino et al. 2010). É ovípara (Marques et al. 2005), e na Caatinga Vitt \& Vangilder (1983) coletaram recém-nascidos em agosto, o que poderia indicar recrutamento na segunda metade da estação seca, enquanto um estudo recente com espécimes do Cerrado indicou reprodução contínua e ninhada de seis a oito ovos (Orofino et al. 2010). O único indivíduo deste trabalho foi coletado no campus da UFV.

Sibynomorphus mikanii (Schlegel, 1837). N = 15 (Figura 4g).

Noturna e terrícola (Laporta-Ferreira et al. 1986, Sawaya et al. 2008), distribui-se pelos planaltos do Brasil central, atlântico e meridional, em áreas de Cerrado e floresta estacional semidecidual (Franco 1994), e na Argentina (Scrocchi et al. 1993), ocorrendo também em áreas alteradas (Albuquerque \& Ferrarezzi 2004, Sawaya et al. 2008), sendo comum até mesmo em ambientes urbanos (e.g. Brites \& Bauab 1988, Barbo 2008, Marques et al. 2009b). Tem dentição áglifa e se alimenta de moluscos sem conchas (Laporta-Ferreira et al. 1986, Marques et al. 2001). Ovípara, possui reprodução restrita aos meses mais quentes e chuvosos do ano (Pizzatto et al. 2008b), com ninhadas entre três e 10 ovos (Laporta-Ferreira et al. 1986, Pizzatto et al. 2008b), havendo registros de desovas comunitárias (Albuquerque \& Ferrarezzi 2004, Braz et al. 2008). Apenas três exemplares possuem dados sobre o ambiente onde foram coletados, sendo provenientes do campus da UFV (um) e do interior de floresta secundária (dois). Sabemos, contudo, que em Viçosa a espécie ocorre ainda em plantações, pastagens, área urbana, e na borda de matas.

Sibynomorphus neuwiedi (Ihering, 1911). N = 29 (Figura 4h).

Noturna e semiarborícola (Pizzatto et al. 2008b, Marques \& Sazima 2004), é endêmica da Mata Atlântica brasileira (Peters \& Orejas-Miranda 1970, Franco 1994), ocorrendo em áreas florestadas e ambientes alterados (Marques \& Sazima 2004, Morato 2005). Tem dentição áglifa (Marques et al. 2001). Laporta-Ferreira et al. (1986) relatam que a espécie se alimenta de moluscos gastrópodes. Porém, Marques \& Sazima (2004) e Palmuti et al. (2009) apontam apenas lesmas Veronicellidae na dieta de $S$. neuwiedi. Ovípara, coloca de quatro a 12 ovos (Marques 1998, Pizzatto et al. 2008b) e apresenta reprodução restrita aos meses mais quentes e chuvosos do ano (Pizzatto et al. 2008b). Onze espécimes provenientes de Viçosa foram coletados no campus da UFV e em área urbana, e outro é proveniente de pastagens abandonadas, em estágio inicial de regeneração. Há ainda um exemplar não coletado, que foi fotografado em borda de mata secundária.

Taeniophallus affinis (Günther, 1858). N =6 (Figura 5a).

Serpente criptozoica e diurna (Sazima \& Haddad 1992, Marques et al. 2001, Pontes \& Rocha 2008), endêmica da Mata Atlântica, distribuindo-se do Nordeste ao Sul do Brasil (Di-Bernardo 1992, Freire \& Silva 2000, Loebmann 2008), em regiões florestadas e abertas (Sazima \& Haddad 1992, Pontes \& Rocha 2008). Áglifa, se alimenta de anuros, lagartos e anfisbênios (Sazima \& Haddad 1992,
Marques et al. 2001, Barbo \& Marques 2003, Barbo \& Sawaya 2008, Pontes \& Rocha 2008, Palmuti et al. 2009, Zacariotti \& Gomes 2010). Ovípara (Marques et al. 2001), não há informações sobre sua reprodução. Todos os exemplares registrados neste estudo são provenientes do campus da UFV e da área urbana de Viçosa.

Taeniophallus occipitalis (Jan, 1863). N = 7 (Figura 5b).

Com hábitos criptozoicos e diurnos (Marques et al. 2005, Sawaya et al. 2008), ocorre do Norte ao Sul da América do Sul, em florestas e áreas abertas (Cunha \& Nascimento 1978, Argôlo 2004, Sawaya et al. 2008). Alimenta-se de anuros e lagartos (Cunha \& Nascimento 1978, Marques et al. 2005) e é ovípara (Marques et al. 2005, Sawaya et al. 2008), não havendo maiores informações sobre sua biologia reprodutiva. Cinco exemplares deste estudo foram coletados no campus da UFV.

Thamnodynastes nattereri. $\mathrm{N}=3$ (Figura 5c).

Semiarborícola e noturna (Marques et al. 2001, Pontes \& Rocha 2008). Os exemplares analisados apresentam características semelhantes a Thamnodynastes sp. 1 de Franco \& Ferreira (2003), os quais sugerem que o nome Thamnodynastes nattereri (Mikan 1820) pode ser aplicável. Distribui-se da Bahia ao Mato Grosso do Sul, seguindo até o Uruguai, em áreas de Mata Atlântica e Cerrado (Franco \& Ferreira 2003). Ocorre em florestas e áreas alteradas (Argôlo 2004, Pontes \& Rocha 2008), tem dentição opistóglifa e alimenta-se de anuros e lagartos (Argôlo 2004, Marques \& Sazima 2004, Pontes \& Rocha 2008). Vivípara, dá à luz em média seis filhotes na segunda metade da estação seca (Pontes \& Rocha 2008). Um dos exemplares examinados é proveniente do campus da UFV. No Parque Estadual da Serra do Brigadeiro, a cerca de $30 \mathrm{~km}$ Nordeste de Viçosa, e em altitudes superiores a $1.000 \mathrm{~m}$, há registros desta espécie forrageando à noite, sobre afloramento rochoso (HCC e RNF obs. pess.), e sobre bromélias de uma lagoa temporária (Lacerda et al. 2009), onde possivelmente poderia apresar indivíduos de Thoropa miliaris e Dendropsophus minutus, presentes nestes ambientes no momento das observações.

Tropidodryas striaticeps (Cope, 1869). N = 12 (Figura 5d).

Semiarborícola e diurna (Marques et al. 2001, StenderOliveira 2008), é endêmica da Mata Atlântica, principalmente em regiões de altitude mais elevada, ocorrendo em matas e áreas antropizadas do Nordeste ao Sul do Brasil (Thomas \& Dixon 1977, Sazima \& Puorto 1993, Stender-Oliveira 2008). Tem dentição opistóglifa (Marques et al. 2001). Indivíduos adultos se alimentam principalmente de presas endotérmicas (mamíferos e aves), enquanto os jovens apresam animais ectotérmicos (répteis e anuros) (Stender-Oliveira 2008), os quais atraem por meio do comportamento de engodo caudal (Sazima \& Puorto 1993). Ovípara, suas ninhadas podem atingir entre um e 18 ovos (Stender-Oliveira 2008). Cardoso \& Albuquerque (2006) registraram uma postura de ovos em cativeiro no mês de janeiro, com nascimento dos filhotes em julho. Stender-Oliveira (2008) encontrou mais espécimes com tamanho de recém-nascidos entre junho e dezembro, com pico em outubro, e fêmeas estocando esperma dos machos. Seis exemplares de Viçosa possuem informações sobre o tipo de ambiente em que se encontravam, tendo sido coletados no campus da UFV e em bairros na zona urbana. Há registro de um exemplar não capturado, proveniente de uma área de cultivo de café, na zona rural. 

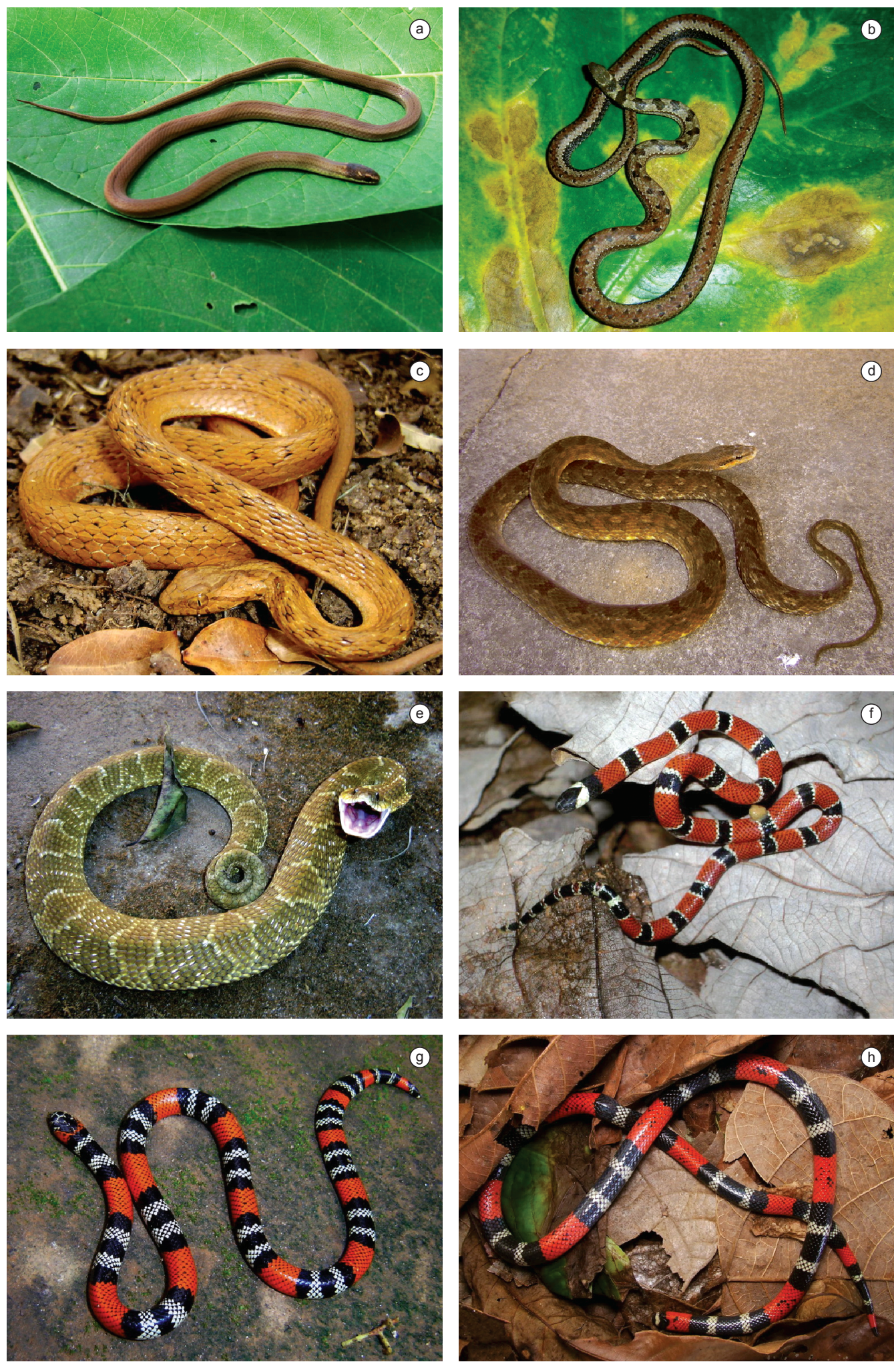

Figura 5. Espécies de serpentes com registro confirmado em Viçosa (quando disponível, preferiu-se ilustrar as pranchas com fotografias de espécimes vivos procedentes de localidades próximas de Viçosa ao invés de material de preservado). a) Taeniophallus affinis (recém-morto); b) Taeniophallus occipitalis; c) Thamnodynastes nattereri (Araponga, $35 \mathrm{~km}$ Leste de Viçosa); d) Tropidodryas striaticeps (Porto Firme, limítrofe a Viçosa a Noroeste); e) Xenodon merremii; f) Micrurus corallinus (Cataguases, $60 \mathrm{~km}$ Sudeste de Viçosa); g) Micrurus frontalis; h) Micrurus lemniscatus carvalhoi (Ferros, $160 \mathrm{~km}$ Norte de Viçosa). Fotos: H. C. Costa, exceto F, de R. C. Siqueira, e H, de D. J. Santana.

Figure 5. Snake species with confirmed register in Viçosa (when available, pictures of live specimens from localities close to Viçosa were preferred to illustrate plates instead of using preserved material). a) Taeniophallus affinis (fresh-killed); b) Taeniophallus occipitalis; c) Thamnodynastes nattereri (Araponga, $35 \mathrm{~km}$ East from Viçosa); d) Tropidodryas striaticeps (Porto Firme, bordering Viçosa in Northwest); e) Xenodon merremii; f) Micrurus corallinus (Cataguases, 60 km Southeast from Viçosa); g) Micrurus frontalis; h) Micrurus lemniscatus carvalhoi (Ferros, $160 \mathrm{~km}$ North from Viçosa). Photos: H. C. Costa, except F, by R. C. Siqueira, and H, by D. J. Santana. 
Xenodon merremii (Wagler, 1824). N = 27 (Figura 5e).

Terrícola e diurna (Vanzolini et al. 1980, Marques et al. 2001, Argôlo 2004), possui ampla distribuição na América do Sul (Perters \& Orejas-Miranda 1970, França et al. 2006), principalmente em áreas abertas (França et al. 2006, Argôlo 2004). Tem dentição áglifa, é batracófaga, com preferência por espécies do gênero Rhinella (=Bufo) (Vanzolini et al. 1980, Vitt \& Vangilder 1983). Ovípara, as populações do Sudeste do Brasil colocam entre seis e 44 ovos e possuem ciclo reprodutivo amplo, do outono à primavera, com recrutamento registrado de janeiro a maio (Pizzatto et al. 2008a). Treze espécimes possuem dados sobre o ambiente de coleta, tendo sido encontrados principalmente no campus da UFV, mas também em área urbana, chácaras, e outras áreas antrópicas associadas a fragmentos de mata secundária.

\section{FAMÍLIA ELAPIDAE}

Micrurus corallinus (Merrem, 1820). N = 3 (Figura 5f).

Criptozoica, com atividade principalmente no início da manhã e no final da tarde (Marques et al. 2001, Marques \& Sazima 2004). Distribui-se ao longo da Mata Atlântica do Nordeste ao Sul do Brasil, com registros também no Paraguai, Argentina e Uruguai (Campbell \& Lamar 2004), em florestas e ambientes alterados (Campbell \& Lamar 2004, Argôlo 2004). Tem dentição proteróglifa e alimenta-se de vertebrados alongados, como cecílias (Gymnophiona), serpentes, anfisbenídeos e alguns lagartos (Marques \& Sazima 1997, Marques \& Sazima 2004). Ovípara, tem reprodução sazonal, com nascimento dos filhotes (dois a 12) no final da estação chuvosa e início da seca (Marques 1996b). Machos estocam espermatozóides na porção final dos ductos deferentes do outono à primavera, quando a cópula ocorre (Almeida-Santos et al. 2006). Não há informações sobre o ambiente onde os espécimes de Viçosa foram coletados.

Micrurus frontalis (Duméril, Bibron \& Duméril, 1854). N = 68 (Figura 5g).

Criptozoica, com hábitos diurnos e noturnos (Sazima \& Abe 1991, Marques et al. 2005), possui ampla distribuição, habitando áreas de Cerrado no Brasil central e florestas estacionais da Mata Atlântica no Sudeste, atingindo também o Paraguai (Silva-Jr. \& Sites 1999). Ocorre naturalmente em áreas abertas e florestadas, podendo também ser encontrada em ambientes antropizados (Sazima \& Abe 1991, Campbell \& Lamar 2004). Tem dentição proteróglifa, e as poucas informações existentes indicam a presença de anfisbenídeos, lagartos e serpentes na sua alimentação (Lema et al. 1983, Sazima \& Abe 1991, Maffei et al. 2009). Ovípara, sua biologia reprodutiva é praticamente desconhecida, mas dados de campo e de padrões de atividade de espécimes do Sudeste do Brasil indicam que aparentemente a cópula ocorre do fim da estação chuvosa à primeira metade da estação seca (Marques et al. 2006). Almeida-Santos et al. (1998) registraram comportamento de combate ritual entre machos, em abril. O recebimento de filhotes no MZUFV por parte da comunidade é relativamente comum no final e início do ano, o que pode ser um indício de que o recrutamento na região ocorra no final da primeira e começo da segunda metade da estação chuvosa. Micrurus frontalis é muito comum em Viçosa, sendo amplamente encontrada em ambientes altamente alterados como áreas urbanas e o campus da UFV, principalmente após chuvas fortes ou longas.
Micrurus lemniscatus carvalhoi Roze, 1967. N = 4 (Figura 5h).

Criptozoica e com atividade diurna e noturna (Sazima \& Abe 1991, Martins \& Oliveira 1998), possui ampla distribuição, ocorrendo na Mata Atlântica do Nordeste ao Sudeste do Brasil e no Cerrado, além de Paraguai e Argentina (Giraudo \& Scrocchi 2002, Campbell \& Lamar 2004). Habita áreas florestadas e abertas, geralmente em locais com bastante umidade, e também ambientes antropizados (Campbell \& Lamar 2004). Proteróglifa, alimenta-se de presas com corpo alongado, como serpentes, anfisbenídeos e peixes (Sazima \& Abe 1991). Ovípara, sua biologia reprodutiva é praticamente desconhecida, mas dados de campo e de padrões de atividade de espécimes do Sudeste do Brasil parecem indicar que a cópula ocorra do fim da estação chuvosa à primeira metade da estação seca (Marques et al. 2006). Apenas um exemplar de Viçosa possui informação sobre o ambiente de coleta, sendo proveniente de área urbana.

\section{FAMÍLIA VIPERIDAE}

Bothrops jararaca (Wied-Neuwied, 1824). N = 93 (Figura 6a).

Terrícola (embora eventualmente utilize substratos arbustivos ou arbóreos) (Sazima 1988, Sazima \& Haddad 1992, Marques et al. 2001, Marques \& Sazima 2004), possui atividade predominantemente crepuscular e noturna (Sazima 1988, Sazima \& Haddad 1992). Na Mata Atlântica do Sudeste do Brasil, Hartmann et al. (2003) encontraram juvenis ativos principalmente durante o dia, no chão. No Brasil distribui-se do Sul do Estado da Bahia ao Rio Grande do Sul, ocorrendo também na Argentina e Paraguai (Campbell \& Lamar 2004), principalmente em áreas florestadas da Mata Atlântica, mas se adaptando também às bordas de matas e áreas antropizadas (Sazima 1992, Sazima \& Haddad 1992). No Município de São Paulo, por exemplo, B. jararaca é a terceira espécie mais coletada pela população (Barbo 2008, Marques et al. 2009b). Tem dentição solenóglifa e apresenta mudança ontogenética na dieta: enquanto jovens apresam principalmente animais ectotérmicos (anuros e lagartos), os quais atraem por meio de engodo caudal (Sazima 1992), os adultos alimentam-se basicamente de roedores (Sazima 1992, Sazima \& Haddad 1992, Hartmann et al. 2003, Marques \& Sazima 2004). Vivípara, possui reprodução bienal, e a cópula ocorre no início da estação seca (Almeida-Santos 2005). As fêmeas estocam o esperma dos machos no útero posterior até o período de fertilização, na primavera (fim da estação seca), e o nascimento dos filhotes (três a 36) ocorre da metade da estação chuvosa ao início da estação seca (Sazima 1992, Almeida-Santos 2005, este estudo). Curiosamente, apesar do ciclo reprodutivo sazonal das fêmeas, os machos estocam espermatozóides nos ductos deferentes ao longo de todo o ano (Almeida-Santos 2005). Em Viçosa, é comum o aparecimento de juvenis nos primeiros meses do ano. Uma fêmea adulta $(C R C=125 \mathrm{~cm})$ foi recebida no MZUFV em maio de 2005, ficando desde então isolada em um recinto. Em 6 de fevereiro de 2006 pariu 36 filhotes, sendo 2 natimortos. A massa da fêmea após o parto foi de $570 \mathrm{~g}$. O comprimento rostro-cloacal médio da ninhada foi $24,4 \mathrm{~cm}$, e a massa média foi de 7,075 g, valores menores que os obtidos para ninhadas de áreas de altitude de São Paulo (26,26 cm e 9,9 g), que tinham em média 17,4 filhotes (Almeida-Santos 2005, Moraes 2008). Contudo, a massa relativa da ninhada de Viçosa $(0,446)$ e dessas localidades de São Paulo $(0,45)$ foi semelhante, mostrando a tendência do tamanho da ninhada e a massa dos filhotes serem inversamente proporcionais (King 1993, Shine 2003). A análise de mais proles provenientes de Viçosa pode ser importante para a realização de melhores 

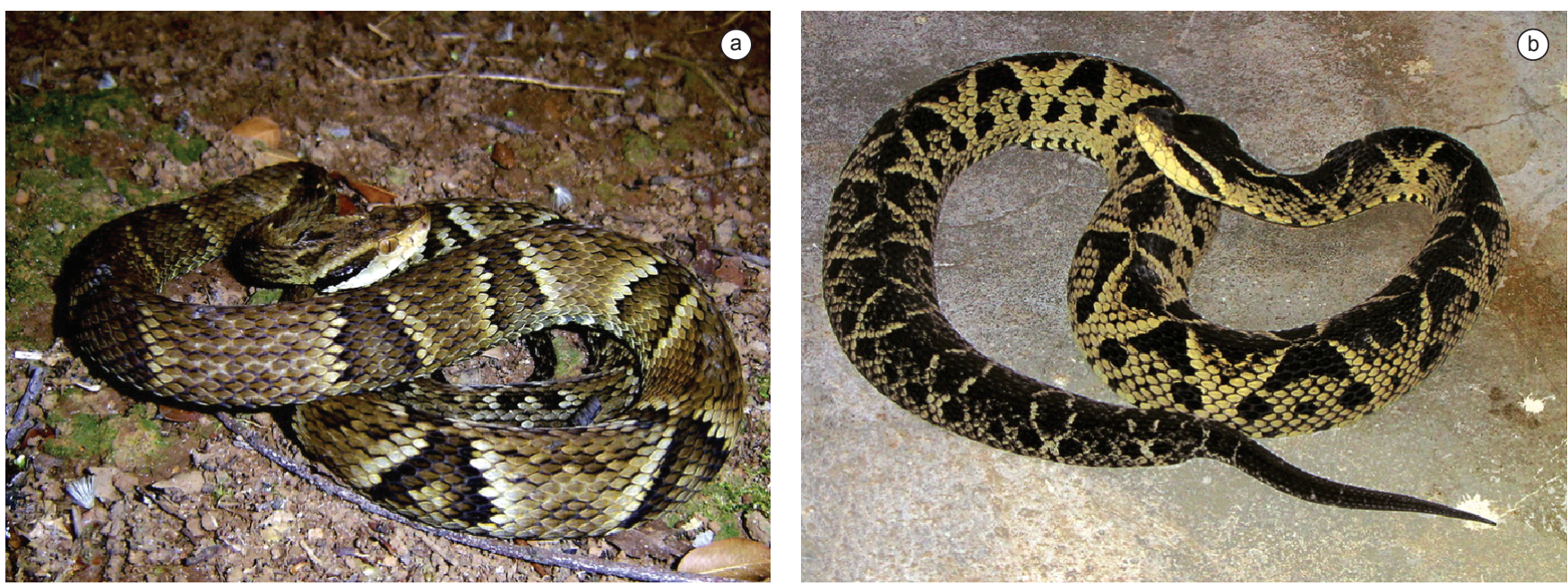

Figura 6. Espécies de serpentes com registro confirmado em Viçosa. a) Bothrops jararaca; b) Bothrops jararacussu. Fotos: H. C. Costa.

Figure 6. Snake species with confirmed register in Viçosa. a) Bothrops jararaca; b) Bothrops jararacussu. Photos: H. C. Costa.

comparações com os resultados existentes para outras populações de B. jararaca. Em Viçosa, B. jararaca é muito encontrada no campus da UFV, havendo registros também para área urbana, chácaras na zona rural e interior de florestas secundárias.

Bothrops jararacussu (Lacerda, 1884). N = 31 (Figura 6b).

Terrícola, com atividade diurna e noturna (Marques \& Sazima 2004), distribui-se principalmente pela Mata Atlântica brasileira do Sul da Bahia ao Rio Grande do Sul, além da Argentina e Paraguai (Campbell \& Lamar 2004), habitando áreas florestadas (Campbell \& Lamar 2004, Marques \& Sazima 2004, Pontes \& Rocha 2008). Tem dentição solenóglifa e apresenta mudança ontogenética na dieta (Marques et al. 2001). Enquanto jovens apresam principalmente animais ectotérmicos (anuros e lagartos), os quais atraem por meio de engodo caudal (Sazima 1992), os adultos alimentam-se basicamente de roedores, mas também de presas ectotérmicas (Marques \& Sazima 2004). Vivípara, há poucas informações sobre sua biologia reprodutiva, que indicam nascimento dos filhotes (13 a 73) na segunda metade e final da estação chuvosa (Marques \& Sazima 2004). Recém-nascidos apresentam dicromatismo sexual, os machos possuindo coloração mais escura que as fêmeas (Marques \& Sazima 2003). Em Viçosa, há registros de B. jararacussu principalmente no campus da UFV, mas também em área urbana e na zona rural, além de espécimes não coletados avistados em bordas de mata secundária.

\section{Espécies com registro incerto no Município de Viçosa}

Duas espécies possuem registro incerto em Viçosa: Xenodon nattereri (Steindachner, 1867) e Bothrops moojeni Hoge, 1966. Apresentamos abaixo algumas informações sobre ambas, e os motivos que nos levaram a considerar tais registros como incertos.

\section{FAMÍLIA DIPSADIDAE}

Xenodon nattereri (Steindachner, 1867). N = 1 (Figura 7a).

Espécie pouco conhecida, possivelmente terrícola e fossorial, com atividade diurna (Sawaya et al. 2008). Possui ampla distribuição, com registros no Nordeste, Centro-oeste, Sudeste e Sul do Brasil (Hoge et al. 1975, Argôlo 2002, Silveira et al. 2004b). Trata-se de uma especialista de hábitat, ocorrendo em áreas abertas com solo arenoso (Sawaya et al. 2008). No Estado de São Paulo há indícios de que suas populações estão em declínio (Marques et al. 1998). É áglifa e alimenta-se de lagartos e de seus ovos (Sawaya et al. 2008). Ovípara, coloca de dois a 10 ovos, havendo indícios de reprodução sazonal, na estação chuvosa (Sawaya et al. 2008).

O único exemplar registrado em Viçosa data de 1980 e não possui informações sobre o coletor nem dados específicos sobre localidade. Alguns municípios próximos a Viçosa possuem remanescentes naturais abertos (Instituto... 2007) que talvez sejam hábitats potenciais para X. nattereri. Embora o longo período de degradação florestal em Viçosa tenha acarretado no surgimento de diversas áreas abertas antes inexistentes (Ribon et al. 2003, Coelho et al. 2005), o fato de $X$. nattereri ser uma especialista de hábitat (Sawaya et al. 2008) torna improvável uma invasão desta espécie no município a partir de áreas abertas naturais adjacentes. Por outro lado, a confirmação da existência de áreas abertas naturais com solo arenoso em Viçosa seria um indício a favor da presença desta serpente. Baseando-se em registros datados desde o século XIX, não há, contudo, provas a favor desta hipótese (Ribon et al. 2003). Em Catas Altas, a cerca de $90 \mathrm{~km}$ Noroeste de Viçosa, e com altitudes semelhantes, dados paleobotânicos indicaram a predominância de campos e matas de galeria entre 48-18 mil anos atrás (Behling 1998). Caso esta situação tenha se repetido em Viçosa, seria possível ao menos uma presença pretérita de $X$. nattereri na região.

Por fim, como os dados que possuímos não fornecem nenhuma indicação que torne seguro afirmar que $X$. nattereri é um componente da fauna de serpentes de Viçosa, preferimos manter seu registro na área de estudo como incerto.

\section{FAMÍLIA VIPERIDAE}

Bothrops moojeni Hoge, 1966. N = 2 (Figura 7b).

Serpente terrícola (eventualmente pode ser encontrada sobre a vegetação), com atividade noturna (Nogueira et al. 2003). Possui ampla distribuição, ocorrendo principalmente em áreas ripárias abertas e florestadas no Cerrado do Brasil central, além de Argentina, Bolívia e Paraguai (Giraudo \& Scrocchi 2002, Campbell \& Lamar 2004). Tem dentição solenóglifa e possui dieta generalista, com mudança ontogenética. Juvenis alimentam-se 

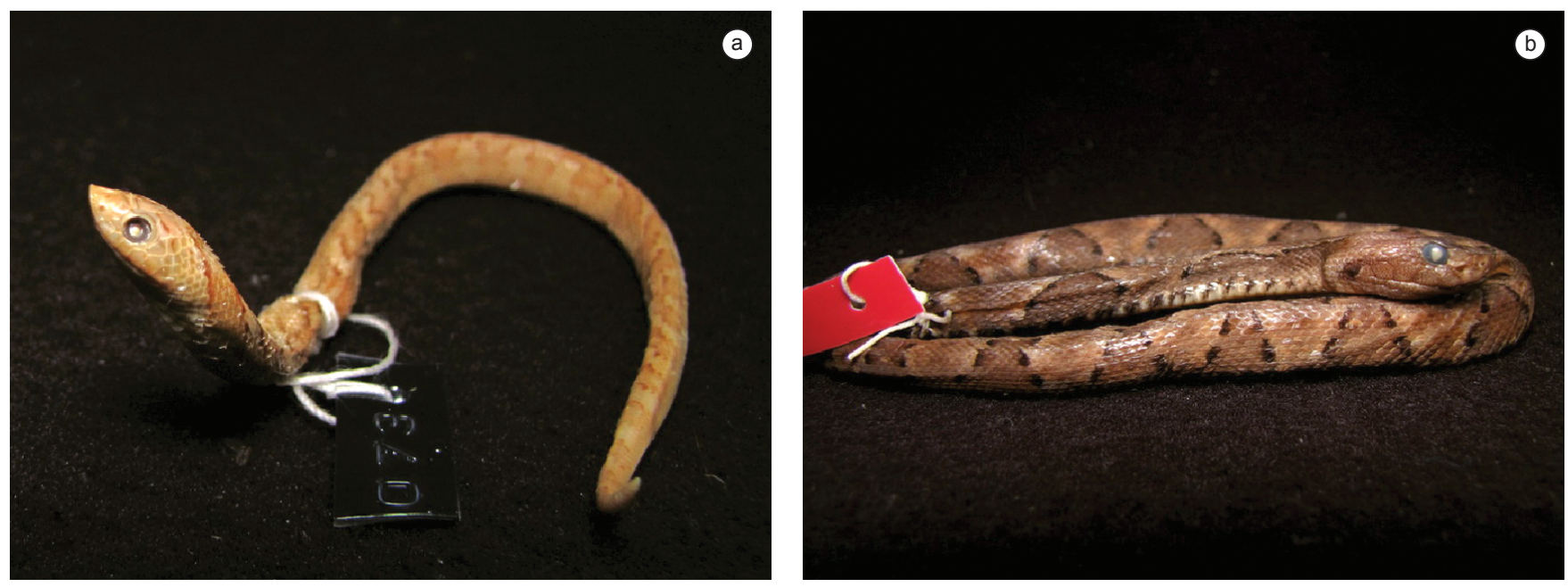

Figura 7. Espécies de serpentes com registro incerto em Viçosa. a) Xenodon nattereri (MZUFV 73); b) Bothrops moojeni (MZUFV 788). Fotos: H. C. Costa. Figure 7. Snake species with uncertain register in Viçosa. a) Xenodon nattereri (MZUFV 73); b) Bothrops moojeni (MZUFV 788). Photos: H. C. Costa.

principalmente de presas ectotérmicas, enquanto adultos ingerem maior porcentagem de presas endotérmicas (Nogueira et al. 2003). Vivípara, tem reprodução sazonal, com nascimento dos filhotes na segunda metade da estação chuvosa (Nogueira et al. 2003), e as fêmeas estocam esperma dos machos após a cópula (Nogueira et al. 2003).

Os dois exemplares de B. moojeni registrados para Viçosa são juvenis datados de 1938 e 1994, ambos provenientes do campus da UFV. Durante muitos anos a UFV comprou lenha de outras regiões para abastecimento de seus fornos, havendo assim a possibilidade de transporte acidental de espécimes para Viçosa. Infelizmente não foi possível obter informações sobre a procedência da lenha que era adquirida pela Universidade para avaliarmos se sua origem coincidiria com a distribuição conhecida de B. moojeni.

A associação de B. moojeni com matas de galeria no Cerrado lhe fornece hábitat favorável para dispersão e manutenção nesse bioma (Nogueira et al. 2003). Contudo, devido à ausência de registros desta espécie nas localidades de Mata Atlântica já inventariadas em Minas Gerais (Bernardes et al. 1994, Feio \& Caramaschi 2002, Bertoluci et al. 2009, Palmuti et al. 2009, SãoPedro \& Pires 2009), não sabemos se tal dispersão poderia ter ocorrido (mesmo que marginalmente) em direção a esse bioma no Estado (à semelhança inversa, por exemplo, da presença do anuro Itapotihyla langsdorffi, típica de Mata Atlântica, em florestas de galeria de Itirapina, no Cerrado de São Paulo (Brasileiro et al. 2005).

Sendo assim, as informações que possuímos não nos permitem afirmar com segurança se B. moojeni poderia ser um componente da fauna de serpentes de Viçosa, nos levando a incluí-la como um registro duvidoso.

\section{Espécies sem registro no Município de Viçosa, mas presentes em municípios próximos}

Cinco serpentes têm registro confirmado em municípios próximos a Viçosa, embora não tenham sido registrados na área de estudo. Abaixo são apresentadas informações básicas sobre cada uma, além de comentários acerca da possibilidade (ou não) de ocorrência em Viçosa.

\section{FAMÍLIA DIPSADIDAE}

Echinanthera melanostigma (Wagler, 1824). $\mathrm{N}=2$ (Figura 8a).

Terrícola, com atividade diurna e noturna (Marques et al. 2001). Possui registros confirmados em Minas Gerais, Rio de Janeiro e São Paulo, em áreas de Mata Atlântica e ecótonos Mata Atlântica-Cerrado a mais de $700 \mathrm{~m}$ de altitude (Di-Bernardo 1992, Silveira et al. 2004a). No MZUFV há dois exemplares provenientes da Serra do Brigadeiro (no complexo da Serra da Mantiqueira), Município de Araponga (aprox. $35 \mathrm{~km}$ Nordeste de Viçosa), em área de mata a mais de $1.000 \mathrm{~m}$ de altitude, que constituem o segundo registro de E. melanostigma para Minas Gerais. Baseando-se nos dados acima, é possível que E. melanostigma ocorra em Viçosa. Echinanthera melanostigma é áglifa, alimenta-se de anuros e é ovípara (Marques et al. 2001), não havendo estudos sobre sua biologia reprodutiva.

Liophis almadensis (Wagler, 1824). N = 1 (Figura 8b).

Terrícola e diurna (Strüssmann \& Sazima 1993, Marques et al. 2005). Generalista quanto ao hábitat (Strüssmann \& Sazima 1993, Argôlo 2004), possui ampla distribuição, ocorrendo desde a ilha de Marajó (Pará), ao longo da costa atlântica até o Rio Grande do Sul, além de registros interioranos na Mata Atlântica, Caatinga, Amazônia, Cerrado e Chacos bolivianos e paraguaios (Dixon 1991 , França et al. 2006, Freitas \& Silva 2007). Tem dentição áglifa, alimenta-se de anuros e é ovípara (Strüssmann \& Sazima 1993, Marques et al. 2001), não havendo estudos sobre sua biologia reprodutiva. O MZUFV possui um exemplar de L. almadensis proveniente de Guaraciaba, município limítrofe a Viçosa, a Noroeste. Sendo uma espécie generalista de hábitat (Argôlo 2004), podendo ser encontrada até mesmo em áreas desmatadas (Strüssmann \& Sazima 1993), sua ocorrência em Viçosa é possível. Caso realmente não seja um componente nativo da fauna viçosense, a baixa exigibilidade ambiental de L. almadensis torna provável uma expansão de sua distribuição em direção a Viçosa nas próximas gerações.

Liophis jaegeri jaegeri (Günther, 1858). N=1 (Figura 8c).

Terrícola e diurna (Marques et al. 2005), ocorre em campos, bordas de matas, alagados, lagoas e banhados do Sudeste do Brasil à costa do Uruguai, a Leste da bacia do Rio Paraná (Dixon 1989, 

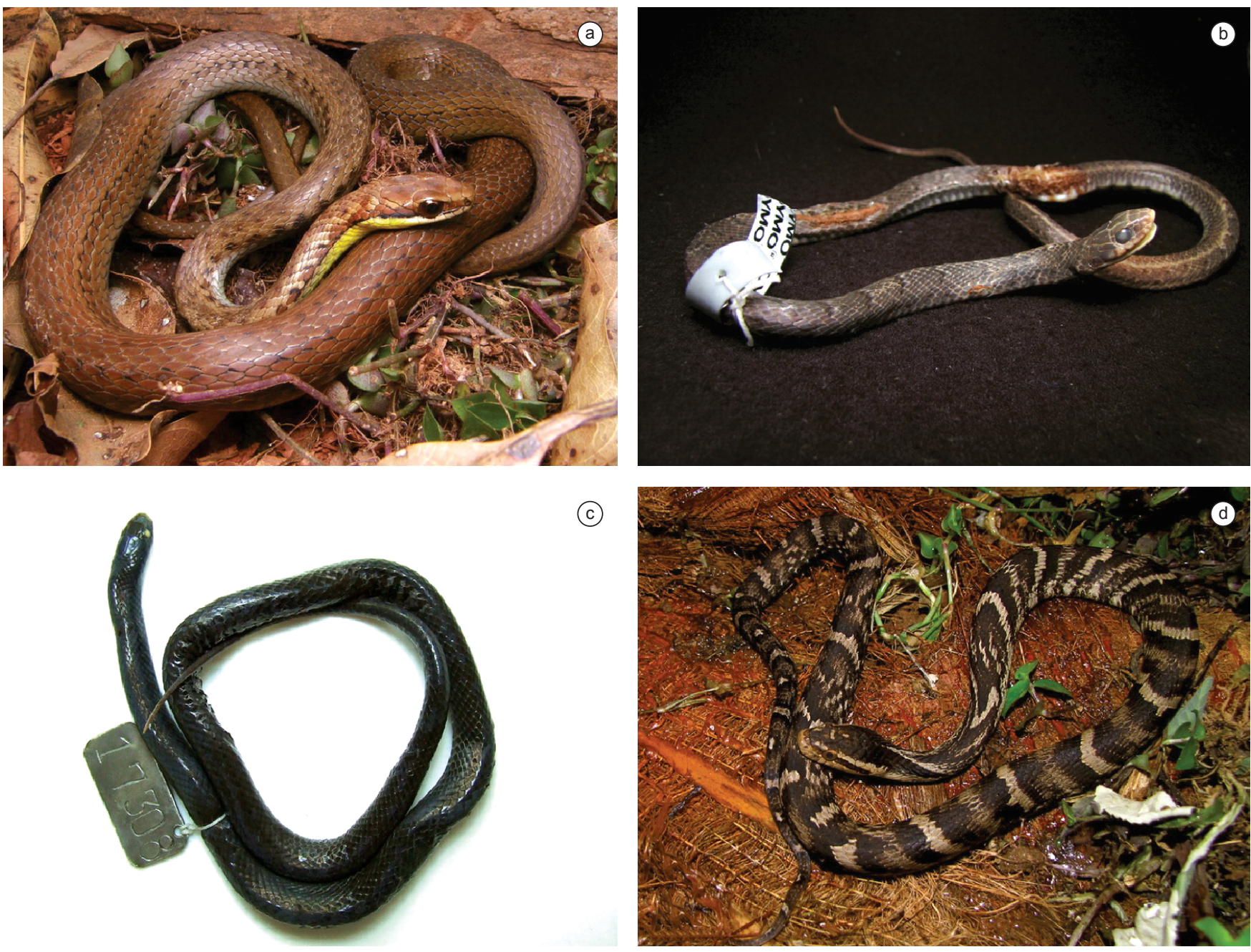

(C)
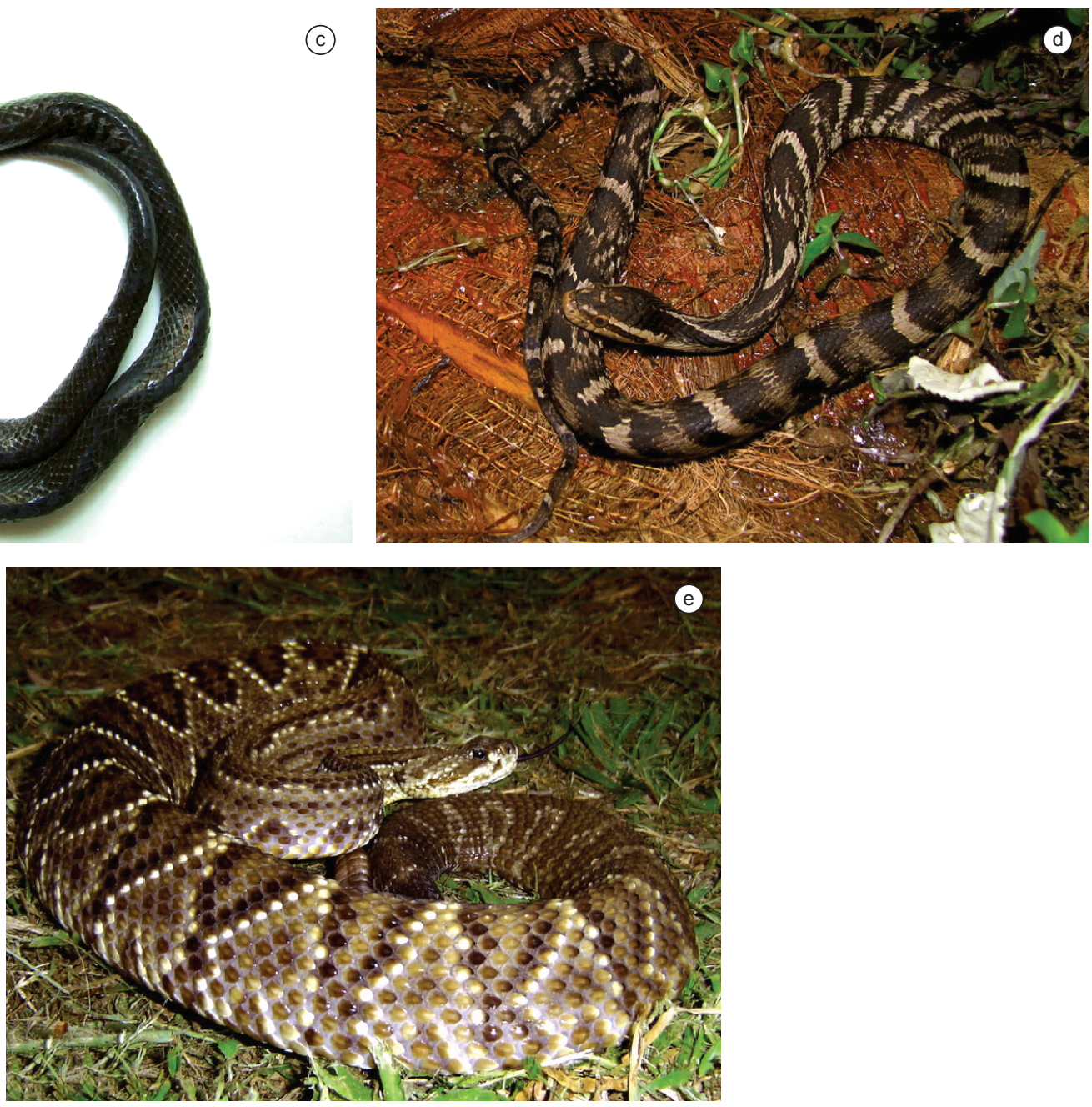

Figura 8. Espécies de serpentes sem registro confirmado em Viçosa, mas presentes em municípios próximos. a) Echinanthera melanostigma (Araponga, 35 km Leste de Viçosa); b) Liophis almadensis (MZUFV 285, Araponga, 35 km Leste de Viçosa); c) Liophis jaegeri jaegeri (IB 17308, Ubá, 30 km Sul de Viçosa); d) Xenodon neuwiedii (Araponga, $35 \mathrm{~km}$ Leste de Viçosa); e) Crotalus durissus (Juiz de Fora, $110 \mathrm{~km}$ Sudoeste de Viçosa [também ocorre em municípios limítrofes a Viçosa]). Fotos: H. C. Costa, exceto C, de D. J. Santana.

Figure 8. Snake species not recorded in Viçosa, but present in nearby municipalities. a) Echinanthera melanostigma (de Araponga, 35 km East from de Viçosa); b) Liophis almadensis (MZUFV 285, Araponga, $35 \mathrm{~km}$ East from Viçosa); c) Liophis jaegeri jaegeri (IB 17308, Ubá, $30 \mathrm{~km}$ south from Viçosa); d) Xenodon neuwiedii (Araponga, $35 \mathrm{~km}$ East from Viçosa); e) Crotalus durissus (Juiz de Fora, $110 \mathrm{~km}$ southwest from Viçosa [it also occurs in municipalities bordering Viçosa]). Photos: H. C. Costa, except C, by D. J. Santana. 
Sawaya et al. 2008, Quintela \& Loebmann 2009). Possui dentição áglifa, alimenta-se quase que exclusivamente de anuros, é ovípara (colocando entre cinco e 13 ovos), com reprodução sazonal e recrutamento na segunda metade da estação chuvosa e início da seca (dezembro a abril) (Frota 2005). O único exemplar deste estudo é proveniente de Ubá, município a aproximadamente $30 \mathrm{~km}$ ao Sul de Viçosa. Liophis j. jaegeri ocorre em diversos outros municípios da Mata Atlântica de Minas Gerais (alguns em áreas de transição com Cerrado) a Norte (Município de Coronel Fabriciano), Nordeste (Município de Mutum) e Oeste (Município de Ouro Preto) de Viçosa (Dixon 1987). Sua presença em Viçosa, seria, portanto, possível.

Xenodon neuwiedii Gunther, 1863. N = 2 (Figura 8d).

Terrícola e diurna (Sazima \& Haddad 1992, Marques \& Sazima 2004), habita principalmente áreas florestadas (embora também possa ocupar áreas alteradas) (Sazima \& Haddad 1992, Marques \& Sazima 2004, Morato 2005). Distribui-se pelo Brasil Central, Sudeste e Sul, além de Argentina e Paraguai (Peters \& Orejas-Miranda 1970, Morato 2005). Posui dentição áglifa e é batracófaga, especialista em apresar sapos do gênero Rhinella (Sazima \& Haddad 1992, Marques \& Sazima 2004). Ovípara, possui ciclo reprodutivo contínuo ao longo de todo o ano (Pizzatto et al. 2008a). Os dois espécimes do presente estudo são oriundos do Parque Estadual da Serra do Brigadeiro, em Araponga (aprox. $35 \mathrm{~km}$ Nordeste de Viçosa). Na região atlântica do Paraná, Morato (2005) encontrou X. neuwiedii ocupando áreas desde o nível do mar até altitudes médias de $1.000 \mathrm{~m}$. Esta adaptabilidade a diferentes gradientes altitudinais torna possível que esta serpente ocorra também em áreas florestadas de Viçosa. Estudos futuros poderão elucidar esta questão.

\section{FAMÍLIA VIPERIDAE}

Crotalus durissus Linnaeus, 1758. N = 6 (Figura 8e).

Terrícola (eventualmente pode subir em árvores (Dayrell et al. 2010)), com atividade predominantemente noturna (Sazima \& Haddad 1992). Possui ampla distribuição, ocorrendo naturalmente em formações abertas de toda a América do Sul, exceto Equador e Chile (Campbell \& Lamar 2004, Wüster et al. 2005). Adapta-se muito bem a áreas desmatadas, colonizando estes ambientes com relativa rapidez (Sazima \& Haddad 1992, Marques et al. 2001, Bastos et al. 2005). Alimenta-se principalmente de roedores (Sazima \& Haddad 1992, Sant'anna \& Abe 2007). Vivípara, existem dados sobre a biologia reprodutiva principalmente de populações do Sudeste brasileiro. A reprodução é bienal e a cópula ocorre no início da estação seca (Almeida-Santos 2005). As fêmeas estocam o esperma dos machos no útero posterior até a fertilização, no fim da estação seca (Almeida-Santos 2005), e nascem entre seis e 22 filhotes na metade da estação chuvosa ao início da estação seca (Melgarejo 2003, Almeida-Santos et al. 2004, Almeida-Santos 2005). Machos estocam espermatozóides nos ductos deferentes ao longo de todo o ano (Almeida-Santos et al. 2004), e. realizam combates rituais no período de procura por fêmeas para a cópula (Almeida-Santos 2005).

No MZUFV há registros de seis exemplares de $C$. durissus provenientes dos municípios de Guaraciaba, Porto Firme e Teixeiras, limítrofes a Viçosa no Noroeste e Norte. A cobertura vegetal nativa desses três municípios é de floresta estacional semidecidual, que hoje se encontra extremamente fragmentada, circundada principalmente por pastagens, capoeiras e cultivos agrícolas (Coelho et al. 2005, Instituto... 2007). Assim como vem sendo registrado em outras regiões originalmente cobertas por matas (Sazima \& Haddad 1992, Marques et al. 2001, Bastos et al.
2005), presume-se que $C$. durissus tenha invadido os municípios citados acima oriunda de áreas onde ocorre naturalmente, como a região de Ouro Branco a Oeste, ecótono de Mata Atlântica e Cerrado (São-Pedro \& Pires 2009). Facilitada pelo extenso processo de desmatamento da Zona da Mata desde o século XIX, C. durissus vem ampliando sua área de distribuição geração a geração, e presumimos que dentro de alguns anos será possível encontrá-la dentro dos limites de Viçosa. Há registros seguros de sua ocorrência também no Município de Ponte Nova (aprox. $25 \mathrm{~km}$ ao Norte de Viçosa), embora sem espécimes coletados. Moradores idosos da zona rural de Ponte Nova relataram em entrevista que $C$. durissus (que é facilmente identificada pelo "chocalho" na ponta da cauda) não ocorria na região em décadas passadas (E. T. da Silva, com. pess.). Isso reforça a ideia de que esta espécie possui alta adaptabilidade a áreas antropizadas, sendo capaz de colonizá-las com rapidez (Bastos et al. 2005).

\section{Considerações Finais}

A maioria das espécies de serpentes com ocorrência confirmada no Município de Viçosa $(\mathrm{N}=23)$ foi registrada no campus da UFV, sete das quais foram coletadas apenas nesta área (Tabela 2). Vinte e uma espécies têm registro em área urbana, enquanto na zona rural e interior de fragmentos florestais foram reportadas apenas nove e oito espécies, respectivamente. Todas aquelas que possuem alguma informação sobre o ambiente ocupado $(\mathrm{N}=30)$ foram encontradas também em locais com elevada intervenção antrópica (área urbana, área rural ou no campus da UFV). Tais resultados sugerem que, de maneira generalizada, as serpentes de Viçosa têm condições de utilizar ambientes modificados pela ação humana. Acreditamos, contudo, ser prematuro fazer maiores considerações sobre adaptações, pois em longo prazo as consequências da antropização sobre a taxocenose são incertas, mas potencialmente desastrosas quanto à conservação.

Dentre as espécies mais registradas neste trabalho, há serpentes altamente peçonhentas (Bothrops spp., Crotalus durissus e Micrurus spp.) e medianamente-peçonhentas (Elapomorphus quinquelineatus, Erythrolamprus aesculapii venustissimus e Philodryas olfersii). Em vista da presença dessas espécies, sugerimos que informações sejam reunidas com a finalidade de subsidiar estudos futuros sobre ofidismo na região.

Alguns trabalhos sugerem que serpentes com hábitos noturnos e dieta baseada em roedores ou invertebrados são mais aptas a sobreviver em ambientes muito alterados, como determinadas regiões urbanizadas (e.g. Sazima \& Manzani 1995, Marques et al. 2009b). Contudo, isso não parece ser um padrão generalizado (ver Carvalho \& Nogueira 1998). As serpentes mais registradas em Viçosa foram Bothrops jararaca $(\mathrm{n}=93)$ e Micrurus frontalis $(\mathrm{n}=68)$. Ambas têm atividade noturna (também diurna na última), mas apenas $B$. jararaca apresa roedores, enquanto a dieta de $M$. frontalis é restrita a vertebrados de corpo alongado. Dentre as 10 serpentes de Viçosa mais registradas em coleções (Bothrops jararaca, Micrurus frontalis, Erythrolamprus aesculapii venustissimus, Bothrops jararacussu, Sibynomorphus neuwiedi, Liophis miliaris, Xenodon merremii, Liophis poecilogyrus poecilogyrus, Philodryas olfersii e Sibynomorphus mikanii), metade é diurna (E. a. venustissimus, X. merremii, L. p. poecilogyrus, L. miliaris e P. olfersii) e apenas três incluem roedores em sua dieta (B. jararaca, B. jararacussu e $P$. olfersii), ao passo que todas as demais se alimentam de presas ectotérmicas (principalmente anuros, mas também lagartos, serpentes e moluscos). É provável, portanto, que a disponibilidade dessas presas influencie mais na composição da fauna de serpentes de Viçosa do que a atividade noturna e a dieta baseada em roedores. Algumas partes da área urbana de Viçosa e praticamente todo o campus da 
Tabela 2. Lista das espécies de serpentes com registros confirmados no Município de Viçosa, Mata Atlântica de Minas Gerais, Sudeste do Brasil, e os respectivos ambientes onde já foram encontradas (informações não existentes para todos os táxons ). AU = Área Urbana; AR = Área Rural; UFV = Campus da Universidade Federal de Viçosa; FS = Floresta Secundária.

Table 2. List of the species of snakes with confirmed records in the Municipality of Viçosa, Atlantic Forest of Minas Gerais, Southeastern Brazil, and the respective habitats where they were found (information not available for all taxa). AU = Urban Area; AR = Rural Area; UFV = Viçosa Federal University Campus; FS = Secondary Forest.

\begin{tabular}{|c|c|c|c|c|}
\hline \multirow{2}{*}{ Táxon } & \multicolumn{4}{|c|}{ Tipo de ambiente } \\
\hline & $\mathbf{A U}$ & $\mathbf{A R}$ & UFV & FS \\
\hline \multicolumn{5}{|l|}{ ANOMALEPIDIDAE } \\
\hline Liotyphlops wilderi (Garman, 1883) & - & - & $\mathrm{X}$ & - \\
\hline \multicolumn{5}{|l|}{ BOIDAE } \\
\hline Corallus hortulanus (Linnaeus, 1758) & - & - & - & - \\
\hline \multicolumn{5}{|l|}{ COLUBRIDAE } \\
\hline Chironius bicarinatus (Wied, 1820) & - & - & - & - \\
\hline Chironius exoletus (Linnaeus, 1758) & - & - & $\mathrm{x}$ & - \\
\hline Chironius quadricarinatus (Boie, 1827) & - & - & $\mathrm{X}$ & - \\
\hline Mastigodryas bifossatus (Raddi, 1820) & $\mathrm{X}$ & - & $\mathrm{x}$ & - \\
\hline Simophis rhinostoma (Schlegel, 1837) & $\mathrm{X}$ & - & $\mathrm{X}$ & - \\
\hline Spilotes pullatus (Linnaeus, 1758) & $\mathrm{X}$ & - & - & - \\
\hline \multicolumn{5}{|l|}{ DIPSADIDAE } \\
\hline Elapomorphus quinquelineatus (Raddi, 1820) & $\mathrm{X}$ & $\mathrm{X}$ & $\mathrm{X}$ & - \\
\hline Erythrolamprus aesculapii (Linnaeus, 1766) & $\mathrm{X}$ & $\mathrm{X}$ & $\mathrm{X}$ & $\mathrm{X}$ \\
\hline Helicops sp. & $\mathrm{X}$ & - & - & - \\
\hline Liophis miliaris (Linnaeus, 1758) & - & - & $\mathrm{X}$ & $\mathrm{X}$ \\
\hline Liophis poecilogyrus poecilogyrus (Wied, 1825) & - & - & $\mathrm{X}$ & - \\
\hline Liophis poecilogyrus schotti (Schlegel, 1837) & - & - & - & - \\
\hline Liophis typhlus (Linnaeus, 1758) & - & - & $\mathrm{X}$ & $\mathrm{X}$ \\
\hline Oxyrhopus clathratus Duméril, Bibron \& Duméril, 1854 & $\mathrm{X}$ & $\mathrm{X}$ & $\mathrm{X}$ & $\mathrm{X}$ \\
\hline Oxyrhopus guibei Hoge \& Romano, 1978 & $\mathrm{X}$ & - & - & - \\
\hline Oxyrhopus petola (Linnaeus, 1758) & $\mathrm{X}$ & - & $\mathrm{X}$ & - \\
\hline Oxyrhopus rhombifer Duméril, Bibron \& Duméril, 1854 & $\mathrm{X}$ & - & - & - \\
\hline Philodryas olfersii (Lichtenstein, 1823) & $\mathrm{X}$ & - & $\mathrm{X}$ & - \\
\hline Philodryas patagoniensis (Girard, 1858) & $\mathrm{X}$ & - & $\mathrm{X}$ & - \\
\hline Pseudoboa nigra (Duméril, Bibron \& Duméril, 1854) & - & - & $\mathrm{X}$ & - \\
\hline Sibynomorphus mikanii (Schlegel, 1837) & $\mathrm{X}$ & $\mathrm{X}$ & - & $\mathrm{X}$ \\
\hline Sibynomorphus neuwiedi (Ihering, 1911) & $\mathrm{X}$ & - & $\mathrm{X}$ & $\mathrm{X}$ \\
\hline Taeniophallus affinis (Günther, 1858) & $\mathrm{X}$ & - & $\mathrm{X}$ & - \\
\hline Taeniophallus occipitalis (Jan, 1863) & - & - & $\mathrm{X}$ & - \\
\hline Thamnodynastes nattereri (Mikan, 1820) & - & - & $\mathrm{X}$ & - \\
\hline Tropidodryas striaticeps (Cope, 1869) & $\mathrm{X}$ & $\mathrm{X}$ & $\mathrm{X}$ & - \\
\hline Xenodon merremii (Wagler, 1824) & $\mathrm{X}$ & $\mathrm{X}$ & $\mathrm{X}$ & - \\
\hline \multicolumn{5}{|l|}{ ELAPIDAE } \\
\hline Micrurus corallinus (Merrem, 1820) & - & - & - & - \\
\hline Micrurus frontalis (Duméril, Bibron \& Duméril, 1854) & $\mathrm{X}$ & $\mathrm{X}$ & - & - \\
\hline Micrurus lemniscatus (Linnaeus, 1758) & $\mathrm{X}$ & - & - & - \\
\hline \multicolumn{5}{|l|}{ VIPERIDAE } \\
\hline Bothrops jararaca (Wied, 1824) & $\mathrm{X}$ & $\mathrm{X}$ & $\mathrm{X}$ & $\mathrm{X}$ \\
\hline Bothrops jararacussu (Lacerda, 1884) & $\mathrm{X}$ & $\mathrm{X}$ & $\mathrm{X}$ & $\mathrm{X}$ \\
\hline TOTAL DE ESPÉCIES: 34 & 21 & 9 & 23 & 8 \\
\hline
\end{tabular}


UFV são circundados por fragmentos florestais (Fig. 1), que além de possuírem microhábitats utilizados pelas serpentes, abrigam diversas espécies de anuros e lagartos que lhes servem de alimento (Dayrell 2009, Costa et al. 2009a). Portanto, embora aparentemente generalistas quanto ao uso de hábitat, as serpentes de Viçosa devem depender em grande parte dos fragmentos florestais da cidade para sua sobrevivência. Situações parecidas também foram observadas por Brites \& Bauab (1988), Carvalho \& Nogueira (1998) e Marques et al. (2009b) nas áreas urbanas de Uberlândia, Cuiabá e São Paulo, respectivamente.

Existe a possibilidade de as espécies mais relacionadas com hábitats abertos não serem nativas da fauna de serpentes de Viçosa. Este seria o caso de Chironius quadricarinatus, Mastigodryas bifossatus, Simophis rhinostoma, Oxyrhopus guibei, O. r. rhombifer, Sibynomorphus mikanii, e Xenodon merremii. Assim como tem sido reportado para Crotalus durissus e O. guibei em outras localidades (Marques et al. 2001, Bastos et al. 2005), talvez estas serpentes tenham se dispersado ao longo das gerações, oriundas de formações abertas naturais adjacentes (e.g. na região de Ouro Preto, a Noroeste) e ocupado áreas desmatadas em Viçosa e outros municípios próximos. Esta ocupação de áreas desmatadas por espécies originárias de formações naturais abertas já foi observada em Viçosa, por exemplo, para o canídeo Chrysocyon brachyurus (Illiger, 1825) (lobo-guará) (Prado et al. 2008), e as aves Vanellus chilensis (Molina, 1782) (quero-quero) e Cariama cristata (Linnaeus, 1766) (seriema) (L. L. Moraes, com. pess.), sendo também uma possível explicação para a presença dos lagartos Tropidurus torquatus e Mabuya dorsivittata no município (Costa et al. 2009a).

O baixo número de espécies encontradas em fragmentos florestais (e em áreas rurais), em contraste com o grande número de registros em áreas antrópicas, é fortemente influenciado pelo padrão de coleta das serpentes em Viçosa. A imensa maioria dos espécimes é capturada por moradores da cidade e pelo corpo de bombeiros da UFV, e trazidas ao MZUFV. É possível ainda que esse padrão de coleta (e não populações mais abundantes per se) seja um dos responsáveis pelo maior número de registros de espécies peçonhentas em relação às demais.

Treze táxons de serpentes não são registrados em Viçosa há pelo menos uma década (último ano de registro entre parênteses): Chironius bicarinatus (1984), C. exoletus (1984), C. quadricarinatus (1985), Corallus hortulanus (1934), Helicops sp. (1998), Liophis poecilogyrus poecilogyrus (1984), Liophis poecilogyrus schotti (1992), Liotyphlops wilderi (1997), Mastigodryas bifossatus (1984), Micrurus corallinus (1973), Micrurus lemniscatus carvalhoi (1986), Oxyrhopus rhombifer rhombifer (1993) e Thamnodynastes nattereri (1994). O investimento em pesquisas de campo é fundamental para elucidar se estas espécies teriam sido extintas do Município de Viçosa, se seriam mais sensíveis às alterações ambientais que as demais, se ocorrem em baixa densidade, possuem uma distribuição marginal na área de estudo, ou simplesmente têm sido subasmostradas pelo método de coleta que consiste basicamente na doação de animais pela população e corpo de bombeiros. Um exemplo é Oxyrhopus guibei, que havia sido registrada pela última vez em 1994, voltando a ser encontrada em 2008. Além disso, espécies como Chironius bicarinatus, C. exoletus, Corallus hortulanus, Liophis p. poecilogyrus e Thamnodynastes nattereri ainda são encontradas em municípios vizinhos ou distantes a menos de $50 \mathrm{~km}$ de Viçosa.

Embora o atual estudo traga informações importantes sobre as serpentes de Viçosa, são necessárias pesquisas de campo que possam fornecer dados mais precisos sobre a riqueza, e principalmente sobre a abundância da ofidiofauna da região. Tais trabalhos também seriam fundamentais, por exemplo, para investigar mais aspectos da história natural das serpentes (e.g. uso de hábitat, dieta e reprodução) e averiguar com mais detalhes a possível presença daquelas espécies com registros não confirmados.

\section{Agradecimentos}

Somos gratos a diversas pessoas e instituições que nos prestaram auxílio: Cláudia M. Herédias Ribas, Daniel Fernandes, Fausto E. Barbo, Francisco L. Franco, Marco Aurélio Sena, Maria da Graça Salomão, Nelson J. da Silva Jr., Paulo S. Bernarde, Renato S. Bérnils, Rômulo Ribon e Thales de Lema, pelo fornecimento de extenso material bibliográfico; Ana Caroline de Lima e Cláudia M. Herédias Ribas, por dividirem informações de suas pesquisas em andamento; Adriano L. Silveira, Daniel Fernandes, Eliza Ribeiro, Renato S. Bérnils, Roberta R. Pinto e Valdir J. Germano, pelo auxílio na identificação de alguns espécimes; Paula H. Valdujo, Paulo S. Bernarde e Renato S. Bérnils, por conselhos e discussões enriquecedoras; Giselle A. Cotta (FUNED), Hussam Zaher e Carolina Castro-Mello (MZUSP), Francisco L. Franco e Valdir J. Germano (IBSP), pelas informações sobre os exemplares mantidos sob seus cuidados; CEDEF/IEF campus UFV, pelo fornecimento de cartas de vegetação da área de estudo; Mário R. Moura, pela confecção do mapa e Fundação SOS Mata Atlântica, pela permissão de uso dos shape files; Diego J. Santana e Ricardo C. Siqueira, pelas fotografias cedidas; vários colegas do Museu de Zoologia João Moojen, por dados importantes sobre suas observações em campo; funcionários da UFV e população de Viçosa, pela doação de serpentes ao MZUFV, criando o alicerce que tornou esta pesquisa viável; Frederico G. França e dois revisores anônimos, pela leitura crítica do manuscrito.

\section{Referências Bibliográficas}

ALBUQUERQUE, C.E. \& FERRAREZZI, H. 2004. A case of communal nesting in the Neotropical snake Sibynomorphus mikanii (Serpentes, Colubridae). Phyllomedusa 3(1):73-77.

ALMEIDA-SANTOS, S.M. \& MARQUES, O.A.V. 2002. Male-male ritual combat in the colubrid snake Chironius bicarinatus from the Atlantic Forest, Southeastern Brazil. Amphibia-Reptilia 23(4):528-533.

ALMEIDA-SANTOS, S.M. 2005. Modelos Reprodutivos em serpentes: estocagem de esperma e placentação em Crotalus durissus e Bothrops jararaca (Serpentes: Viperidae). Tese de doutorado, Universidade de São Paulo, São Paulo.

ALMEIDA-SANTOS, S.M., AGUIAR, L.F.S. \& BALESTRIN, R.L. 1998. Micrurus frontalis (Coral Snake). Male Combat. Herpetol. Rev. 29(4):242.

ALMEIDA-SANTOS, S.M., LAPORTA-FERREIRA, I.L., ANTONIAZZI, M.M. \& JARED. C. 2004. Sperm storage in males of the snake Crotalus durissus terrificus (Crotalinae: Viperidae) in Southeastern Brazil. Comp. Biochem. Physiol. 139:169-174.

ALMEIDA-SANTOS, S.M., PIZZATTO, L., \& MARQUES, O.A.V. 2006. Intra-Sex Synchrony and Inter-Sex Coordination in the Reproductive Timing of the Atlantic Coral Snake Micrurus Corallinus (Elapidae) in Brazil. Herpetol. J. 16(4):371-376.

ANDRADE, R.O. \& SILVANO, R.A.M. 1996. Comportamento alimentar e dieta da "Falsa-Coral" Oxyrhopus guibei Hoge \& Romano (Serpentes Colubridae). Rev. Bras. Zoo. 13(1):143-150.

ARGÔLO, A.J.S. 1998. Simophis rhinostoma. Geographic Distribution. Herpetol. Rev. 29(3):179.

ARGÔLO, A.J.S. 2001. Oxyrhopus clathratus. Geographic Distribution. Herpetol. Rev. 32(1):61.

ARGÔLO, A.J.S. 2002. Lystrophis nattereri. Geographic Distribution. Herpetol. Rev. 33(2):150.

ARGÔLO, A.J.S. 2004. As Serpentes dos cacauais do Sudeste da Bahia. Ed. UESC, Ilhéus.

BARBO, F.E. \& MARQUES, O.A.V. 2003. Do aglyphous colubrid snakes prey on live amphisbaenids able to bite? Phyllomedusa 2(2):113-114.

BARBO, F.E. \& SAWAYA, R.J. 2008. Amphisbaenians, Municipality of São Paulo, State of São Paulo, Southeastern Brazil. Checklist 4(1):5-11. 
BARBO, F.E. 2008. Os Répteis no Município de São Paulo: aspectos históricos, diversidade e conservação. In Além do Concreto: contribuições para a proteção da biodiersidade paulistana (L.R. Malagoli, F.B. Bajestero \& M. Whately, eds). Instituto Socioambiental, São Paulo, p.234-267.

BARROS-FILHO, J.D. 2008. Répteis do Parque Nacional da Serra dos Órgãos: novos registros, comentários e perspectivas. Esp. Geogr. 11(1):73-86.

BARTLETT, R.D. \& BARTLETT, P. 2003. Reptiles and Amphibians of the Amazon: An Ecotourist's Guide. University Press of Florida, Gainesville.

BASTOS, E.G.M., ARAÚJO, A.F.B. \& SILVA, H.R. 2005. Records of the Rattlesnake Crotalus durissus terrificus (Laurenti) (Serpentes, Viperidae) in the State of Rio de Janeiro, Brazil: a possible case of invasion facilitated by deforestation. Rev. Bras. Zool. 22(3):812-815.

BEHLING, H. 1998. Late Quaternary vegetational and climatic changes in Brazil. Rev. Palaeobot. Palynol. 99:143-156.

BERNARDE, P.S. \& MACHADO, R.A. 2000. Oxyrhopus petola digitalis (NCN). Prey. Herpetol. Rev. 31(4):247-248.

BERNARDE, P.S. \& MACHADO, R.A. 2002. Fauna reptiliana da bacia do rio Tibagi. In A Bacia do Rio Tibagi (M.E. Medri, E. Bianchini, O.A. Shibatta \& J.A. Pimenta, eds.). Londrina, p. 291-296.

BERNARDES, A.T., NASCIMENTO, L.B., FEIO, R.N. \& CARAMASCHI, U. 1994. Herpetofauna. In Anais do Workshop sobre pesquisas prioritárias para o Parque Estadual do Rio Doce (M.A. Drumond, P.M. Andrade \& F.J. Cerceaux, orgs.). Instituto Estadual de Florestas \& Engevix Engenharia S.A., Belo Horizonte, p. 49-56.

BÉRNILS, R.S. 2010. Brazilian Reptiles - List of Species. Sociedade Brasileira de Herpetologia http://www.sbherpetologia.org.br/checklist/ repteis.htm (último acesso em 06/05/2010).

BÉRNILS, R.S., BATISTA, M.A. \& BERTELLI, P.W. 2001. Cobras e lagartos do Vale: levantamento das espécies de Squamata (Reptilia, Lepidosauria) da Bacia do Rio Itajaí, Santa Catarina, Brasil. Rev. Estud. Amb. 3(1):69-79.

BÉRNILS, R.S., NOGUEIRA, C.C. \& XAVIER-DA-SILVA, V. 2009. Répteis. In Biota Minas: diagnóstico do conhecimento sobre a biodiversidade no Estado de Minas Gerais - Subsídio ao Programa BIOTA MINAS (G.M. Drummond, C.S. Martins, M.B. Greco \& F. Vieira, eds.). Fundação Biodiversitas, Belo Horizonte, p.251-280.

BERTOLUCI, J., CANELAS, M.A.S, EISEMBERG, C.C., PALMUTI, C.F.S. \& MONTINGELLI, G.G. 2009. Herpetofauna da Estação Ambiental de Peti, um fragmento de Mata Atlântica do Estado de Minas Gerais, Sudeste do Brasil. Biota Neotrop. 9(1): http://www.biotaneotropica.org.br/v9n1/ en/abstract?inventory+bn01409012009 (último acesso em 11/08/2009).

BIZERRA, A.F., JORDÃO, R.S. \& SAZIMA, I. 1994. Simophis rhinostoma (NCN). Diet. Herpetol. Rev. 25(2):72-73.

BONFIGLIO, F. \& LEMA, T. 2006. Ofiofagia em Liophis miliaris (Serpentes, Colubridae). Biociências 14(2):221-222.

BRASILEIRO, C.A., SAWAYA, R.J., KIEFER, M.C. \& MARTINS, M. 2005. Amphibians of an open Cerrado fragment in Southeastern Brazil. Biota Neotrop. 5(2): http://www.biotaneotropica.org.br/v5n2/pt/ abstract?article+BN00405022005 (último acesso em 26/12/2009).

BRAZ, H.B.P., FRANCO, F.L. \& ALMEIDA-SANTOS, S.M. 2008. Communal egg-laying and nests-sites of the Goo-eater Snake, Sibynomorphus mikanii (Dipsadidae, Dipsadinae) in Southeastern Brazil. Herpetol. Bull. 106:26-30.

BRAZ, H.B.P., LOPES, P.H., ROCHA, M.M.T. \& FURTADO, M.F.D. 2006. Liophis miliaris (Common water snake): Cannibalism. Herpetol. Bull. 97:36-37.

BRITES, V.L.C. \& BAUAB, F.A. 1988. Fauna Ofidiana do Município de Uberlândia, Minas Gerais - Brasil. I. Ocorrência na Área Urbana. Rev. Cent. Ciênc. Bioméd. Univ. Fed. Uberlândia 4(1):3-7.

CACCIALI, P., SCOTT-Jr., N., GUENTHER, R., SAWAYA, R.J., BRUSQUETTI, F. \& BAUER, F. 2009. Taxonomic Status of the False Coral Snake Genus Simophis (Peters, 1860) (Serpentes: Colubridae: Colubrinae) from Paraguay and Brazil. J. Herpetol. 43(4):698-703.
CAMPBELL, J.A. \& LAMAR, W.W. 2004. The Venomous Reptiles of the Western Hemisphere. Cornell University Press, Ithaca.

CARDOSO, S.R.T. \& ALBUQUERQUE, C.C. 2006. Tropidodryas striaticeps (Vine-snake): Reproduction. Herpetol. Bull. 98:34-35.

CARDOSO, S.R.T., ROCHA, M.M.T. \& PUORTO, G. 2001. Elapomorphus quinquelineatus (Raddi's Lizard-eating Snake). Reproduction. Herpet. Rev. 32(4):262-263.

CARVALHO, M.A. \& NOGUEIRA, F. 1998. Serpentes da área urbana de Cuiabá Mato Grosso: aspectos ecológicos e acidentes ofídicos associados. Cad. Saúde Púb. Rio de Janeiro 14(4):753-763.

CARVALHO-Jr., R.R. \& NASCIMENTO, L.B. 2005. Bothrops leucurus (White-tailed Lancehead). Geographic Distribution. Herpetol. Rev. 36(4):469.

CENTENO, F.C., SAWAYA, R.J. \& MARQUES, O.A.V. 2008. Snake assemblage of Ilha de São Sebastião, Southeastern Brazil: comparison to mainland. Biota Neotrop. 8(3): http://www.biotaneotropica.org.br/v8n3/ pt/abstract?article+bn00608032008 (último acesso em 26/12/2009).

COELHO, D.J.S., SOUZA, A.L. \& OLIVEIRA C.M.L. 2005. Levantamento da cobertura florestal natural da Microrregião de Viçosa, MG, utilizandose imagens de Landsat 5. Rev. Árvore 29(1):17-24.

CONDEZ, T.H., SAWAYA, R.J. \& DIXO. M. 2009. Herpetofauna dos remanescentes de Mata Atlântica da região de Tapiraí e Piedade, SP, Sudeste do Brasil. Biota Neotropica 9(1): http://www.biotaneotropica. org.br/v9n1/en/abstract?inventory+bn01809012009 (último acesso em 11/08/2009).

COSTA, H.C., FERNANDES, V.D., RODRIGUES, A.C. \& FEIO, R.N. 2009a. Lizards and Amphisbaenians, Municipality of Viçosa, State of Minas Gerais, Southeastern Brazil. Check List 5(3):732-745.

COSTA, H.C., PINTO, R.R. \& SANTANA, D.J. 2009b. Reptilia, Leptotyphlopidae, Leptotyphlops salgueiroi Amaral, 1954: Distribution extension and geographic variation. Check List 5(4):783-786.

CUNHA, O.R. \& NASCIMENTO, F.P. 1978. Ofídios da Amazônia X - As cobras da região Leste do Pará. Publ. Av. Museu Paraense Emílio Goeldi $31: 1-218$.

CURCIO, F.F. 2008. Revisão Taxonômica e variação geográfica do gênero Erythrolamprus Boie, 1826 (Serpentes, Xenodontinae). Tese de doutorado, Universidade de São Paulo, São Paulo.

CURCIO, F.F., PIACENTINI, V.Q. \& FERNANDES, D. 2009. On the status of the snake genera Erythrolamprus Boie, Liophis Wagler and Lygophis Fitzinger (Serpentes, Xenodontinae). Zootaxa 2173:66-68.

DAYRELL, J.S. 2009. Estrutura da comunidade de anfíbios em poças temporárias em um fragmento de Mata Atlântica de Minas Gerais. Dissertação de mestrado, Universidade Federal de Viçosa, Viçosa.

DAYRELL, J.S., COSTA, H.C., FEIO, R.N. \& DRUMMOND, L.O. 2010. Crotalus durissus (South American Rattlesnake). Arboreal Habitat Use. Herpetol. Rev. 41(1):89-90.

DEPARTAMENTO NACIONAL DE METEOROLOGIA. 1992. Normais climatológicas (1961-1990). SPI/EMBRAPA, Brasília.

DIAS, L.G., FEIO, R.N. \& SANTOS, P.S. 2008. New record of Bothriopsis bilineata (Wied, 1825) (Serpentes, Viperidae) in the Atlantic Forest of Minas Gerais, with a discussion on its conservation. Lundiana 9(1):7576.

DI-BERNARDO, M. 1992. Revalidation of the genus Echinanthera Cope, 1894 and its conceptual amplification (Serpentes, Colubridae). Com. Mu. Ciên. PUCRS, Ser. Zoo, 5(13):225-256.

DIXON, J.R. \& KOFRON, C.P. 1983. The Central and South American Anomalepid Snakes of the Genus Liotyphlops. Amphibia-Reptilia 4:241-264.

DIXON, J.R. 1983. Taxonomic status of the South American snakes Liophis miliaris, L. amazonicus, L. chrysostomus, L. mossoriensis and L. purpurans. Copeia 3:791-802.

DIXON, J.R. 1987. Taxonomy and geographic variation of Liophis typhlus and related "green" species of South America (Serpentes: Colubridae). Ann. Carnegie Mus. 56(8):173-191. 
DIXON, J.R. 1989. A Key and Checklist of the Neotropical Snake Genus Liophis with Country List and Maps. Smithsonian Herpetol. Ser. Ser. 79:1-40.

DIXON, J.R. 1991. Geographic variation and taxonomy of Liophis almadensis (Wagler) (Serpentes: Colubridae), and description of a new species of Liophis from Argentina and Bolivia. Texas J. Sci. 43(3):225-236.

DIXON, J.R., WIEST Jr., J.A. \& CEI, J.M. 1993. Revision of the Neotropical snake genus Chironius Fitzinger (Serpentes, Colubridae). Monogr. Mus. Reg. Sci. Nat. Torino 13:1-279.

DROEGE, S., CYR, A. \& LARIVÉE, J. 1998. Checklists: an under-used tool for the inventory and monitoring of plants and animals. Conserv. Biol. 12(5):1134-1138.

FEIO, R.N. \& CARAMASCHI, U. 2002. Contribuição ao conhecimento da herpetofauna do Nordeste do Estado de Minas Gerais, Brasil. Phyllomedusa 1(2):105-111.

FENWICK, A.M., GUTBERLET-Jr., R.L., EVANS, J.A. \& PARKINSON, C.L. 2009. Morphological and molecular evidence for phylogeny and classification of South American pitvipers, genera Bothrops, Bothriopsis, and Bothrocophias (Serpentes: Viperidae). Zoo. J. Linn. Soc. 156(3):617-640.

FERNANDES, D.F. 2006. Revisão sistemática de Liophis poecilogyrus (WiedNeuwied 1825) (Serpentes: Colubridae). Tese de doutorado, Universidade Federal do Rio de Janeiro, Rio de Janeiro.

FONTES, L.E.F., FERNANDES, R.B.A., RODRIGUES, J.S. \& FERNANDESFILHO, I. 2006. Recursos hídricos e uso do solo no Município de Viçosa, MG. In Recursos Hídricos e Percepção Ambiental no Município de Viçosa MG (L.E.F. Fontes, R.B.A. Fernandes \& J.S. Rodrigues, eds.). Ambiente Brasil Centro de Estudos, Viçosa, p. 1-20.

FOWLER, I.R., SALOMÃO, M.G. \& JORDÃO, R.S. 1998. A description of the female reproductive cycle in four species of the neotropical colubrid snake Philodryas (Colubridae, Xenodontinae). The Snake 28:71-78.

FRANÇA, F.G.R, MESQUITA, D.O. \& COLLI.G.R. 2006. A checklist of snakes from Amazonian savannas in Brazil, housed in the Coleção Herpetológica da Universidade de Brasília, with new distribution records. Occ. Pap. Okla. Mus. Nat. Hist. 17:1-13.

FRANÇA, F.G.R., MESQUITA, D.O., NOGUEIRA, C.C. \& ARAÚJO, A.F.B. 2008. Phylogeny and Ecology Determine Morphological Structure in a Snake Assemblage in the Central Brazilian Cerrado. Copeia 1:23-38.

FRANCO, F.L. \& FERREIRA, T.G. 2003. Descrição de uma nova espécie de Thamnodynastes Wagler, 1830 (Serpentes, Colubridae) do Nordeste brasileiro, com comentários sobre o gênero. Phyllomedusa 1(2):57-74.

FRANCO, F.L. 1994. O gênero Sibynomorphus Fitzinger, 1843 no Brasil (Colubridae: Xenodontinae, Dipsadini). Dissertação de mestrado, Pontifícia Universidade Católica do Rio Grande do Sul, Porto Alegre.

FRANCO, F.L., MARQUES, O.A.V., SKUK, G. \& PORTO, M. 1998. Répteis na Estação Veracruz. Veracel Celulose, Eunápolis.

FREIRE, E.M.X. \& SILVA, S.M.T. 2000. Geographic Distribution: Taeniophallus affinis. Herpetol. Rev. 31(3):187.

FREIRE, E.M.X. 1999. Geographic Distribution: Oxyrhopus guibei. Herpetol. Rev. 30(1):55.

FREITAS, M.A. \& SILVA, T.F.S. 2007. Guia Ilustrado: a herpetofauna das caatingas e áreas de altitudes do Nordeste brasileiro. USEB, Rio de Janeiro.

FROTA, J.G. 2005. Biologia reprodutiva e dieta de Liophis jaegeri jaegeri (Günther, 1858) (Serpentes, Colubridae, Xenodontinae). Dissertação de mestrado, Pontifícia Universidade Católica do Rio Grande do Sul, Rio Grande do Sul.

FUNDAÇÃO SOS MATA ATLÂNTICA \& INSTITUTO NACIONAL DE PESQUISAS ESPACIAIS - INPE. 2008. Atlas dos remanescentes florestais de Mata Atlântica. Período 2000-2005. São Paulo.

GIRAUDO, A.R. \& SCROCCHI, G.J. 2002. Argentinian Snakes: an annotated checklist. Smithsonian Herpetol. Serv. Ser. 132:1-53.
GIRAUDO, A.R., ARZAMENDIA, V. \& CACCIALI, P. 2006. Geographic variation and taxonomic status of the southernmost populations of Liophis miliaris (Linnaeus, 1758) (Serpentes: Colubridae). Herpetol. J. 16(2):2213-220.

GRANTSAU, R. 1991. As cobras venenosas do Brasil. Bandeirante, São Paulo.

GREENE, H.W. 1997. Snakes. The evolution of mystery in nature. University of California Press, California.

HADDAD, C.F.B. 1998. Biodiversidade dos Anfíbios no Estado de São Paulo. In Biodiversidade do Estado de São Paulo, Brasil: síntese do conhecimento ao final do século XX, 6: vertebrados (C.A. Joly \& C.E.M. Bicudo, orgs.). FAPESP, São Paulo, p.17-26.

HARTMANN, P.A. \& MARQUES, O.A.V. 2005. Diet and habitat use of two sympatric Philodryas (Colubridae) in South Brazil. Amphibia-Reptilia 26(1):25-31.

HARTMANN, P.A., HARTMANN, M.T. \& GIASSON, L.O. 2003. Uso do hábitat e alimentação em juvenis de Bothrops jararaca (Serpentes, Viperidae) na Mata Atlântica do Sudeste do Brasil. Phyllomedusa 2(1):35-41

HARTMANN, P.A., HARTMANN, M.T. \& MARTINS, M. 2009a. Ecologia e história natural de uma taxocenose de serpentes no Núcleo Santa Virgínia do Parque Estadual da Serra do Mar no Sudeste do Brasil. Biota Neotropica 9(3): http://www.biotaneotropica.org.br/v9n3/pt/ abstract?article+bn03609032009 (último acesso em 26/12/2009).

HARTMANN, P.A., HARTMANN, M.T. \& MARTINS, M. 2009b. Ecology of a snake assemblage in the Atlantic Forest of Southeastern Brazil. Pap. Av. Zool. 49(27):343-360.

HAUZMAN, E., RIBEIRO-DA-COSTA, A.C.O. \& SCARTOZONNI, R.R. 2005. Spilotes pullatus (Tiger Ratsnake). Reproduction. Herpetol. Rev. 36(3):328.

HENDERSON, R.W. 1997. A Taxonomic Review of the Corallus hortulanus Complex of Neotropical Tree Boas. Carib. J. Sci. 33(3-4):198-221.

HOGE, A.R., CORDEIRO C.L. \& ROMANO S.A.L. 1975. Posição Taxonômica de Lystrophys nattereri (Steindachner) [Serpentes, Colubridae]. Mem. Inst. Butantan 39:37-50.

HOLLIS, J.L. 2006. Phylogenetics of the genus Chironius Fitzinger, 1826 (Serpentes, Colubridae) based on morphology. Herpetologica 62(4):435-453.

HOSER, R. 2009. A reclassification of the Rattlesnakes; species formerly exclusively referred to the Genera Crotalus and Sistrurus. Aust. J. Herpetol. 6:1-21.

INSTITUTO FEDERAL DE FLORESTAS - IEF. 2007. Mapa da flora nativa e dos reflorestamentos de Minas Gerais. Coordenadoria de Monitoramento CM/CEDEF.

JORDÃO, R.S. \& BIZERRA, A.F. 1996. Reprodução dimorfismo sexual e atividade de Simophis rhinostoma (Serpentes Colubridae). Rev. Bras. Zool. 56(3):507-512.

KAWASHITA-RIBEIRO, R.A. 2007. História natural de uma taxocenose de serpentes da RPPN Acurizal e áreas adjacentes, Serra do Amolar, borda Oeste do Pantanal, Corumbá, Mato Grosso do Sul, Brasil. Dissertação de mestrado, Universidade Federal do Mato Grosso, Cuiabá.

KING, R.B. 1993. Determinants of offspring number and size in the brown snake, Storeria dekayi. J. Herpetol. 27(2):175-185.

LACERDA, J.V.A., ASSIS, B., SANTANA, D.J. \& FEIO, R.N. 2009. Anurans in bromeliads, Parque Estadual da Serra do Brigadeiro, State of Minas Gerais, Southeastern Brazil. Check List 5(4):800-806.

LAPORTA-FERREIRA, I.L., SALOMÃO, M.G. \& SAWAYA, P. 1986. Biologia de Sibynomorphus (Colubridae - Dipsadinae) - Reprodução e hábitos alimentares. Rev. Bras. Zool. 46(4):793-799.

LEMA, T., ARAÚJO, M.L. \& AZEVEDO, A.C.P. 1983. Contribuição ao conhecimento da alimentação e do modo alimentar de serpentes do Brasil. Com. Mus. Ciênc. PUCRS, Ser. Zool. 26:41-121. 
LEVANDEIRA-GONÇALVES, M.A.P., AGUIAR, F.V.O., CAMARGO, J.V.C., BARROS-FILHO, J.D. \& CARVALHO-E-SILVA, S.P. 2007. Levantamento preliminar da fauna de répteis do Parque Nacional da Serra dos Órgãos. In Ciência e Conservação na Serra dos Órgãos (C. Cronemberger \& E.B. Viveiros-de-Castro, eds.). Parque Nacional da Serra dos Órgãos, Teresópolis, p.135-153.

LOEBMANN, D. 2008 Geographic Distribution: Echinanthera affinis (Günther's forest snake). Herpetol. Rev. 39(2):241.

MACHADO, R.A., BERNARDE, P.S. \& MORATO, A.A. (1998). Liophis miliaris (Common Water Snake). Prey. Herpetol. Rev. 29(1):45.

MAFFEI, F., NASCIMENTO, G.R. \& GARRONE NETO, D. 2009. Predation on the lizard Ameiva ameiva (Sauria: Teiidae) by a coral snake Micrurus frontalis (Serpentes: Elapidae) in Brazil. Herpetol. Notes 2:235-237.

MARQUES, O.A.V. \& MURIEL, A.P. 2007. Reproductive biology and food habits of the swamp racer Mastigodryas bifossatus from Southeastern South America. Herpetol. J. 17(2):104-109.

MARQUES, O.A.V. \& PUORTO, G. 1991. Padrões cromáticos, distribuição e possível mimetismo em Erythrolamprus aesculapii (Serpentes, Colubridae). Mem. Inst. Butantan 53(1):127-134.

MARQUES, O.A.V. \& PUORTO, G. 1994. Dieta e comportamento alimentar de Erythrolamprus aesculapii, uma serpente ofiófaga. Rev. Bras. Biol. 54(2):253-259.

MARQUES, O.A.V. \& SAZIMA, I. 1997. Diet and feeding behavior of the coral snake, Micrurus corallinus, from the Atlantic forest of Brazil. Herpetol. Nat. Hist. 5(1):88-93.

MARQUES, O.A.V. \& SAZIMA, I. 2003. Bothrops jararacussu (Jararacussu). Sexual Dichromatism. Herpetol. Rev. 34(1):62.

MARQUES, O.A.V. \& SAZIMA, I. 2004. História natural dos répteis da Estação Ecológica Juréia-Itatins. In Estação Ecológica Juréia-Itatins: ambiente físico, flora e fauna (O.A.V. Marques \& W. Duleba, eds.). Holos, Ribeirão Preto, p.257-277.

MARQUES, O.A.V. 1996a. Biologia reprodutiva da cobra-coral Erythrolamprus aesculapii Linnaeus (Colubridae) no Sudeste do Brasil. Rev. Bras. Zool. 13(3):747-753.

MARQUES, O.A.V. 1996b. Reproduction, seasonal activity and growth of the Micrurus corallinus (Serpentes, Elapidae). Amphibia-Reptilia 17:277-285.

MARQUES, O.A.V. 1998. Composição Faunística História Natural e Ecologia de Serpentes da Mata Atlântica na Região da Estação Ecológica Juréia-Itatins São Paulo SP. Tese de doutorado, Universidade de São Paulo, São Paulo.

MARQUES, O.A.V., ALMEIDA-SANTOS, S.M. \& RODRIGUES, M.G. 2006. Activity Patterns in Coralsnakes, genus Micrurus (Elapidae), in South and Southeastern Brazil. South Amer. J. Herpetol. 1(2):99-105.

MARQUES, O.A.V., ALMEIDA-SANTOS, S.M., RODRIGUES, M.G. \& CAMARGO, R. 2009a. Mating and Reproductive Cycle in the Neotropical Colubrid Snake Chironius bicarinatus. South Amer. J. Herpetol. 4(1):76-80.

MARQUES, O.A.V., ETEROVIC, A. \& SAZIMA, I. 2001. Serpentes da Mata Atlântica: guia ilustrado para a Serra do Mar. Holos, Ribeirão Preto.

MARQUES, O.A.V., ETEROVIC, A., STRÜSSMANN, C. \& SAZIMA, I. 2005. Serpentes do Pantanal: guia ilustrado. Holos, Ribeirão Preto.

MARQUES, O.A.V., MARTINS, M. \& ABE, A.S. 1998. Estudo diagnóstico da diversidade de répteis do Estado de São Paulo. In Biodiversidade do Estado de São Paulo: síntese do conhecimento ao final do século XX (R.M.C. Castro, org). FAPESP, São Paulo, p.29-38.

MARQUES, O.A.V., PEREIRA, D.N., BARBO, F.E., GERMANO, V.J. \& SAWAYA, R.J. 2009b. Os Répteis do Município de São Paulo: diversidade e ecologia da fauna pretérita e atual. Biota Neotropica 9(2): http://www. biotaneotropica.org.br/v9n2/pt/abstract?article+bn02309022009 (último acesso em 16/08/2009).

MARTINS, M. \& OLIVEIRA, M.E. 1998. Natural history of snakes in forests of the Manaus region Central Amazonia Brazil. Herpetol. Nat. Hist. 6(2):78-150.
MASCHIO, G.F., DI-BERNARDO \& MELCHIORS, J. 2004. Oxyrhopus rhombifer rhombifer (NCN). Diet. Herpetological Review 35(1):71.

MELGAREJO, A.R. 2003. Serpentes Peçonhentas do Brasil. In Animais peçonhentos no Brasil: Biologia, Clínica e Terapêutica dos Acidentes. (J.L.C. Cardoso, F.O.S. França, F.H. Wen, C.M.S. Málaque \& V. Haddad Jr., eds.) Sarvier, São Paulo, p. 33-61.

MICHAUD, E.J. \& DIXON, J. 1989. Prey ítems of 20 species of the neotropical colubrid snake genus Liophis. Herpetol. Rev. 20(2):39-41.

MITTERMEIER, R.A., GIL, P.R., HOFFMANN, M., PILGRIM, J., BRROKS, T., MITTERMEIER, C.G., LAMOREUX, J. \& FONSECA, G.A.B. 2004. Hotspots Revisited. Cemex, Mexico City.

MORAES, R.A. 2008. Variações em caracteres morfológicos e ecológicos em populações de Bothrops jararaca (Serpentes: Viperidae) no Estado de São Paulo. Dissertação de Mestrado, Universidade de São Paulo, São Paulo.

MORATO, S.A.A. 2005. Serpentes da Região Atlântica do Estado do Paraná, Brasil: diversidade, distribuição e ecologia. Tese de doutorado, Universidade Federal do Paraná, Curitiba.

MYERS, C. 1974. The systematics of Rhadinaea (Colubridae), a genus of New World Snakes. Bulletin of the Amer. Mus. Nat. Hist. 153(1):1-262.

MYERS, C.W. \& CADLE, J.C. 1994. A new genus for South American snakes related to Rhadinaea obtusa Cope (Colubridae) and resurrection of Taeniophallus Cope for the Rhadinaea brevirostris group. Amer. Mus. Novit. 3102:1-33.

MYERS, N., MITTERMEIER, R.A, MITTERMEIER, C.G., FONSECA, G.A.B. \& KENT, J. 2000. Biodiversity hotspots for conservation priorities. Nature 403:853.858.

NOGUEIRA, C., SAWAYA, R.J. \& MARTINS, M. 2003. Ecology of the Pitviper, Bothrops moojeni, in the Brazilian Cerrado. J. Herpetol. 37(4):653-659.

OLIVEIRA, M.A. \& DELLA-LUCIA, T.M.C. 1993. Inquilinismo de Phylodryas olfersii (Reptilia, Squamata, Colubridae) em ninhos de Acromyrmex subterraneus (Hymenoptera, Formicidae, Attini). Rev. Bras. Entomol. 37(1):113-115.

OROFINO, R.P., PIZZATTO, L. \& MARQUES, O.A.V. 2010. Reproductive biology and food habits of Pseudoboa nigra (Serpentes: Dipsadidae) from the Brazilian cerrado. Phyllomedusa 9(1):53-61.

OUTEIRAL, A.B. \& LEMA, T. 2003. Estudo morfológico comparativo hemipeniano das subespécies de Msatigodryas bifossatus (Raddi, 1820) (Serpentes: Caenophidia: Colubridae: Colubrinae). Acta Biol. Leopol. 25(1):113-122.

PALMUTI, C.F.S., CASSIMIRO, J. \& BERTOLUCI, J. 2009. Food habits of snakes from the RPPN Feliciano Miguel Abdala, an Atlantic Forest fragment of Southeastern Brazil. Biota Neotrop. 9(1): http://www.biotaneotropica. org.br/v9n1/pt/abstract?short-communication+bn02209012009 (último acesso em 16/08/2009).

PARPINELLI, L. \& MARQUES, O.A.V. 2008. Seasonal and daily activity in the Pale-headed Blindsnake Liotyphlops beui (Serpentes: Anomalepididae) in Southeastern Brazil. South Amer. J. Herpetol. 3(3):207-212.

PARPINELLI, L. 2008. História Natural da cobra cega Liotyphlops beui (Serpentes: Anomalepididae). Dissertação de mestrado, Universidade Estadual Paulista "Júio Mesquita de Filho", São José do Rio Preto.

PASSOS, P. \& BRANDÃO, F. 2002. Drymoluber dichrous. Geographic Distribution. Herpetol. Rev. 33(4):324.

PEREIRA, M.F.V. 2005. Contradições de uma "cidade científica": processo de urbanização e especialização territorial em Viçosa (MG). Cam. Geogr. 18(16):197-206.

PETERS, J.A. \& OREJAS-MIRNDA, B. 1970. Catalogue of Neotropical Squamata Part I. Snakes. Bull. U.S. Nati. Mus. 297:1-347.

PINTO, R.R. 2006. Biologia Reprodutiva e Dieta de Chironius flavolineatus (Jan, 1863) e Chironius quadricarinatus (Boie, 1827) no Brasil (Serpentes: Colubridae). Dissertação de mestrado, Universidade Federal do Rio de Janeiro, Rio de Janeiro. 
PINTO, R.R., \& FERNANDES, R. 2004. Reproductive biology and diet of Liophis poecilogyrus poecilogyrus (Serpentes, Colubridae) from Southeastern Brazil. Phyllomedusa 3(1):9-14.

PINTO, R.R., FERNANDES, R. \& MARQUES, O.A.V. 2008. Morphology and diet of two sympatric colubrid snakes, Chironius flavolineatus and Chironius quadricarinatus (Serpentes: Colubridae). Amphibia-Reptilia 29(2):149-160.

PIZZATTO, L. \& MARQUES, O.A.V. 2002. Reproductive biology of the false coral snake Oxyrhopus guibei (Colubridae) from Southeastern Brazil. Amphibia-Reptilia 23(4):495-504.

PIZZATTO, L. \& MARQUES, O.A.V. 2006. Interpopulational variation in sexual dimorphism, reproductive output, and parasitism of the water snake Liophis miliaris (Colubridae), in the Atlantic forest of Brazil. Amphibia-Reptilia 27(1):37-46.

PIZZATTO, L. \& MARQUES, O.A.V. 2007. Reproductive ecology of Boine snakes with emphasis on Brazilian species and a comparison to Pythons. South Amer. J. Herpetol. 2(2):107-122.

PIZZATTO, L. 2003. Reprodução de Liophis miliaris (Serpentes: Colubridae) no Brasil: influência histórica e variações geográficas. Dissertação de mestrado, Universidade Estadual de Campinas, Campinas.

PIZZATTO, L., CANTOR, M., OLIVEIRA, J.L., MARQUES, O.A.V., CAPOVILLA, V. \& MARTINS, M. 2008b. Reproductive Ecology of Dipsadine Snakes, with Emphasis on South American Species. Herpetologica 64(2):168-179.

PIZZATTO, L., JORDÃO, R.S. \& MARQUES, O.A.V. 2008a. Overview of reproductive strategies in Xenodontini (Serpentes: Colubridae: Xenodontinae) with new data for Xenodon neuwiedii and Waglerophis merremii. J. Herpetol. 42(1):153-162.

PONTES, J.A.L. \& ROCHA, C.F.D. 2008. Serpentes da Serra do Mendanha, Rio de Janeiro, RJ: ecologia e conservação. Technical Books, Rio de Janeiro.

PRADO, M.R., ROCHA, E.C. \& LESSA, G.M. 2008. Mamíferos de médio e grande porte em um fragmento de Mata Atlântica, Minas Gerais, Brasil. Rev. Árvore 32(4):741-749.

PRUDENTE, A.L.C. \& FEIO, R.N. 2001. Siphlophis longicaudatus Geographic Distribution. Herpetol. Rev. 32(2):125.

PRUDENTE, A.L.C. 2003. Diagnóstico das coleções brasileiras de répteis In Coleções Biológicas de Apoio ao Inventário, Uso Sustentável e Conservação da Biodiversidade (A.L. Peixoto, org.). Instituto de Pesquisas Jardim Botânico do Rio de Janeiro, Rio de Janeiro, p.183-198.

QUINTELA, F.M. \& LOEBMANN, D. 2009. Guia ilustrado: os répteis da região costeira do Extremo Sul do Brasil. USEB, Pelotas.

RIBON, R., SIMON, J.E. \& MATTOS, G.T. 2003. Bird Extinctions in Atlantic Forest Fragments of the Viçosa Region, Southeastern Brazil. Conserv. Biol. 17(6): 1827-1839.

RODRIGUES, M.T. 2005. A conservação dos répteis brasileiros: os desafios para um país megadiverso. Megadiversidade 1(1):87-94.

SALLES, R.O.L., WEBER, L.N., SILVA-SOARES, T. 2010. Reptiles, Squamata, Parque Natural Municipal da Taquara, Municipality of Duque de Caxias, State of Rio de Janeiro, Southeastern Brazil. Check List 6(2):280-286.

SANT'ANNA, S. \& ABE, A. 2007. Diet of the rattlesnake Crotalus durissus in Southeastern Brazil (Serpentes, Viperidae). Stud. Neotrop. Faun. Environm. 42(3):169-174.

SANTANA, G.G., VIEIRA, W.L.S., PEREIRA-FILHO, G.A., DELFIM, F.R., LIMA, Y.C.C. \& VIEIRA, K.S. 2008. Herpetofauna em um fragmento de Floresta Atlântica no estado da Paraíba, Região Nordeste do Brasil. Biotemas 21(1):75-84.

SANTOS-Jr., A.F. 2005. Análise da variação e taxonomia de Echinanthera occipitalis (Jan, 1863) (Serpentes, Colubridae) com a descrição de uma nova espécie. Tese de doutorado, Pontifícia Universidade Católica do Rio Grande do Sul, Porto Alegre.

SANTOS-Jr., A.F., DI-BERNARDO, M. \& LEMA, T. 2008. New species of the Taeniophallus occipitalis Group (Serpentes, Colubridae) from Eastern Amazonia, Brazil. J. Herpetol. 42(3):419-426.
SÃO-PEDRO, V.A. \& PIRES, M.R.S. 2009. As serpentes da região de Ouro Branco, extremo Sul da Cadeia do Espinhaço, Minas Gerais. Rev. Ceres 56(2):166-171.

SAVAGE, J.M. 2002. The Amphibians and Reptiles of Costa Rica: a herpetofauna between two continents, between two seas. University of Chicago Press, Chicago.

SAWAYA, R.J., MARQUES, O.A.V. \& MARTINS, M. 2008. Composição e história natural das serpentes de Cerrado de Itirapina, São Paulo, Sudeste do Brasil. Biota Neotropica 3(2): http://www.biotaneotropica.org.br/v8n2/ pt/abstract?inventory+bn01308022008 (último acesso em 16/08/2009).

SAZIMA, I. \& ABE, A.S. 1991. Habits of five Brazilian snakes with coralsnake pattern including a summary of defensive tactics. Stud. Neotrop. Faun. Environm. 26(3):159-164.

SAZIMA, I. \& HADDAD, C.F.B. 1992. Répteis da Serra do Japi: notas sobre história natural. In História natural da Serra do Japi: ecologia e preservação de uma área florestal do Sudeste do Brasil (L.P.C. Morellato, org.). UNICAMP/FAPESP, Campinas, p.212-236.

SAZIMA, I. \& MANZANI, P.R. 1995. As cobras que vivem numa reserva florestal urbana. In Ecologia e preservação de uma floresta tropical urbana: Reserva de Santa Genebra. (P.C. Morellato \& H.F. Leitão-Filho, eds). Ed. UNICAMP, Campinas, p.78-82.

SAZIMA, I. \& PUORTO, G. 1993. Feeding technique of juvenile Tropidodryas striaticeps: probable caudal luring in a colubrid snake. Copeia 1993(1):222-226.

SAZIMA, I. 1988. Um estudo de biologia comportamental da jararaca, Bothrops jararaca, com uso de marcas naturais. Mem. Inst. Butantan 50(3):83-99.

SAZIMA, I. 1992. Natural history of the jararaca pitviper, Bothrops jararaca, in Southeastern Brazil. In Biology of the pitvipers (J.A. Campbell, E.D. \& Brodie, eds.). Selva, Tyler, p.199-216.

SAZIMA, I. 2001. Répteis. In Intervales: fundação para a conservação e produção florestal do Estado de São Paulo (C. Leonel, ed.). Fundação Florestal, São Paulo, p.148-158.

SCHARGEL, W.E., FUENMAYOR, G.R. \& MYERS, C.W. 2005. An Enigmatic New Snake from Cloud Forest of the PenínSula de Paria, Venezuela (Colubridae: Genus Taeniophallus?). Amer. Mus. Novit. 3484:1-22.

SCROCCHI, G. \& DRUZ, F.B. 1993. Description of a new species of the genus Lystrophis Cope and a revalidation of Lystrophis pulcher (Jan, 1863), (Serpentes; Colubridae). Pap. Av. Zool. 38(10):171-185.

SCROCCHI, G., PORTO, M. \& REY, L. 1993. Descriptcion de una especie nueva y situación del género Sibynomorphus (Serpentes: Colubridae) en la Argentina. Rev. Bras. Biol. 53(2):197-208.

SHINE, R. 2003. Reproductive stategies in snakes. Proc. Royal Soc. B 270:995-1004.

SILVA, M.A.A. 2007. Revisão Taxonômica de Liophis typhlus (Linnaeus, 1758) (Serpentes: Colubridae). Dissertação de mestrado. Universidade Federal do Pará, Museu Paraense Emílio Goeldi, Belém.

SILVA-Jr., N.J. \& SITES, J.W. 1999. Revision of the Micrurus frontalis complex (Serpentes: Elapidae). Herpetol. Monogr. 13:142-194.

SILVANO, D.L., COLLI, G.R., DIXO, M.B.O., PIMENTA, B.V.S. \& WIEDERHECKER, H.C. 2003. Fragmentação de Ecossistemas: causas, efeitos sobre a biodiversidade e recomendações de políticas públicas. Ministério do Meio Ambiente, Brasília.

SILVEIRA, A.L., COSTA, E.R. \& SALLES, L.M. 2004b. Geographic Distribution: Lystrophis nattereri. Herpetol. Rev. 35(4):412.

SILVEIRA, A.L., PIRES, M.R.S. \& COTTA, G.A. 2004a. Geographic Distribution: Echinanthera melanostigma. Herpetol. Rev. 35(4):410.

SOUSA, P.A.G. \& FREIRE, E.M.X. 2008. Geographic Distribution: Philodryas patagoniensis. Herpetol. Rev. 39(2):243.

STENDER-OLIVEIRA, F. 2008. Ecologia alimentar e reprodutiva de duas espécies de Tropidodryas (Serpentes, Colubridae) da Mata Atlântica. Dissertação de mestrado, Universidade de São Paulo, São Paulo. 
STRÜSSMANN, C. \& SAZIMA, I. 1993. The Snake Assemblage of the Pantanal at Poconé, Western Brazil: Faunal Composition and Ecological Summary. Stud. Neotrop. Faun. Environm. 28(3):157-168.

THOMAS R.A. \& DIXON, J.A. 1977. A new systematic arrangement for Philodryas serra (Schlegel) and Philodryas pseudoserra Amaral (Serpentes: Colubridae). Pearce Sellards Ser. 27:1-20.

THOMAS, R.A. 1976. A Revision of the South American colubrid snake genus Philodryas Wagler, 1890. Tese de doutorado, Texas A. \& M. University.

UETZ, P. 2008. How Many Species? http://www.reptile-database.org/db-info/ SpeciesStat.html (último acesso em 26/12/2009).

VALVERDE, O. 1958. Estudo Regional da Zona da Mata, de Minas Gerais. Rev. Bras. Geogr. 20(1):3-82.

VANZOLINI, P.E., RAMOS-COSTA, A.M.M. \& VITT, L.J. 1980. Répteis das caatingas. Academia Brasileira de Ciências, Rio de Janeiro.

VANZOLINI. P.E. 1986. Addenda and Corrigenda to the Catalogue of Neotropical Squamata Part I Snakes. Smithsonian Herpetol. Inform. $70: 1-26$.

VIANELLO, R.L. \& ALVES, A. R. 1991. Meteorologia Básica e Aplicações. Imprensa Universitária, Viçosa.

VIDAL, N., DEWYNTER, M. \& GOWER, D.J. 2010. Dissecting the major American snake radiation: a molecular phylogeny of the Dipsadidae Bonaparte (Serpentes, Caenophidia). C.R. Biolog. 333:48-55.

VITT, L.J. \& VANGILDER, L.D. 1983. Ecology of a snake community in Northeastern Brazil. Amphibia-Reptilia 4(2-4):273-296.

WÜSTER, W., FERGUSON, J.E., QUIJADA-MASCAREÑAS, J.A., POOK, C.E., SALOMÃO, M.G. \& THORPE, R.S. 2005. Tracing an invasion: landbridges, refugia, and the phylogeography of the Neotropical rattlesnake (Serpentes: Viperida: Crotalus durissus). Mol. Ecol. 14:1095-1108.
WÜSTER, W., SALOMÃO, M.G., QUIJADA-MASCAREÑAS, J.A., THORPE, R.S. \& BBBSP. 2002. Origins and evolution of the South American pitviper fauna: evidence from mitochondrial DNA sequence analysis. In Biology of the vipers (G.W. Schuett, M. Höggren, M.E. Douglas \& H.W. Greene, eds.). Eagle Mountain Publishing, Eagle Mountain, p. 111-128.

YUKI, R.N. \& LEMA, T. 2005. Análise comparativa entre as cobras d'água meridionais (Helicops carinicaudus (Wied, 1825) e Helicops infrataeniatus Jan, 1865), com a descrição do crânio e hemipênis (Serpentes: Colubridae: Xenodontinae). Com. Mus. Ciên. Tecnol. PUCRS, Ser. Zool. 18(2):85-128.

ZACARIOTTI, R.L. \& GOMES, C.A. 2010. Diet of the Black-headed Forest racer Taeniophallus affinis Günther, 1858 in the Brazilian Atlantic forest. Herpetol. Notes 3:11-12.

ZAHER, H. \& CARAMASCHI, U. 1992. Sur le statut taxinomique d'Oxyrhopus trigeminus et O. guibei (Serpentes, Xenodontinae). Bull. Mus. Natl. d'Hist. Nat. 14(3-4):205-827.

ZAHER, H., GRAZZIOTIN, F.G., CADLE, J.E, MURPHY, R.W., MOURALEITE, J.C. \& BONATTO, S.L. 2009. Molecular phylogeny of advanced snakes (Serpentes, Caenophidia) with an emphasis on South American Xenodontines: a revised classification and descriptions of new taxa. Pap. Av. Zool. 49(11):115-153.

ZAHER, H., SCROCCHI, G. \& MASIERO, R. 2008. Rediscovery and redescription of the type of Philodryas laticeps Werner, 1900 and the taxonomic status of $P$. oligolepis Gomes, 1921 (Serpentes, Colubridae). Zootaxa 1940:25-40.

ZUG, G.H., VITT, L.J. \& CALDWELL, J.P. 2001. Herpetology: an introductory biology of amphibians and reptiles. $2^{\text {nd }}$ ed. Academic Press, San Diego. 


\section{Apêndice}

Material examinado. Acrônimos correspondem à coleção onde cada exemplar encontra-se depositado: Instituto Butantan (IBSP), Fundação Ezequiel Dias (FUNED) e Museu de Zoologia João Moojen (MZUFV). Quando não indicado, os espécimes são provenientes de Viçosa.

VIÇOSA: Bothrops jararaca - IBSP 26395-26400; MZUFV 190, 192, 194, 195, 263, 264, 266, 271, 272, 276, 280, 282, 283, 295, 296, $300,332,373,384,387,396,397,418,467,471,478,541,631,716,787,790,1005,1006,1008,1014,1024-1026,1030,1033-1036,1065$, 1123, 1142-1147, 1218-1223, 1275, 1276, 1279-1285, 1293, 1302, 1309-1312, 1393, 1419, 1420, 1423, 1477, 1479, 1480, 1503, 1527, 1528, 1565, 1585, 1605, 1606, 1684. Bothrops jararacussu - IBSP 26337-26340, 31725; MZUFV 191, 254, 255, 275, 335, 386, 388, 399, 400, 415-417, 429, 436, 459, 847, 848, 1002, 1254, 1255, 1306-1308, 1366, 1425, 1564, 1604, 1629. Bothrops moojeni - MZUFV 193, 788. Chironius bicarinatus - MZUFV 046, 049, 051, 143, 145, 168. Chironius exoletus - MZUFV 012, 013, 029, 043, 044, 047, 056, 116, 291, 317. Chironius quadricarinatus - MZUFV 004, 006, 022, 048, 050, 053, 054, 333, 357, 358. Corallus hortulanus - IBSP 8848. Crotalus durissus - Teixeiras: MZUFV 452. Porto Firme: MZUFV 385, 1080. Guaraciaba: MZUFV 1110, 1119, 1300. Echinanthera melanostigma - Parque Estadual da Serra do Brigadeiro, Araponga: MZUFV 1445, 1658. Elapomorphus quinquelineatus - MZUFV 014, 030, 057, 058, $123,179,383,456,710,764,800,833,970,999,1019,1042,1239,1268,1303,1314,1398,1467,1476,1523,1529$, 1630. Erythrolamprus aesculapii venustissimus - FUNED 77; MZUFV 001, 182, 183, 186-189, 200-208, 211, 212, 214, 215, 292, 330, 354, 370, 508, 817, 965, 1017, 1141, 1193, 1195, 1365, 1394. Helicops sp. - MZUFV 960. Liophis almadensis - Guaraciaba: MZUFV 285. Liophis jaegeri jaegeri - Ubá: IB 17308. Liophis miliaris - MZUFV 009, 027, 063, 065-067, 072, 074, 077, 080, 095-097, 108, 113, 114, 127, 130-132, 163, 167, 980, 1192, 1246, 1272, 1487, 1562. Liophis poecilogyrus poecilogyrus - IBSP 8892, 8893, 20919; MZUFV 002, 021, 078, 081-087, 089, 090, 101, 120, 125, 148, 151, 157, 162, 164, 165, 169, 176, 218, 293. Liophis poecilogyrus schotti - MZUFV 178, 494. Liophis typhlus brachyurus - MZUFV 068, 372, 1247, 1278, 1482, 1522, 1554. Liotyphlops wilderi-IBSP 8894; MZUFV 339, 340, 524, 912. Mastigodryas bifossatus - IBSP 20889; MZUFV 032-034, 036, 037, 040, 100, 102, 106. Micrurus corallinus - MZUFV 223, 224, 246. Micrurus frontalis - IBSP 43017, 49100; MZUFV 220-222, 227-233, 245, 248, 250, 316, 355, 431, 438, 439, 441, 472, 474, 475, 480, 509, 510, 518-523, 537, 632-634, 672-675, 721, 728-731, 736, 793, 809, 818, 828, 966, 968, 986, 1044, 1084, 1099, 1196, 1245, 1248, 1269, 1296, 1297, 1372, 1468, 1469, 1472, 1481, 1516, 1521, 1550, 1656. Micrurus lemniscatus carvalhoi - IBSP 31382; MZUFV 219, 238, 371. Oxyrhopus clathratus MZUFV 091, 369, 445, 525, 709, 849, 1000, 1202, 1270, 1304, 1351. Oxyrhopus guibei-MZUFV 185, 781, 1549, 1622, 1633. Oxyrhopus petola digitalis - MZUFV 005, 010, 483, 997, 1225, 1267, 1286, 1313, 1364, 1387, 1388, 1531, 1638. Oxyrhopus rhombifer rhombifer MZUFV 714. Philodryas olfersii - MZUFV 003, 015, 060, 064, 104, 105, 156, 172, 253, 315, 331, 442, 536, 715, 816, 1021, 1023, 1031, 1043, 1064, 1076, 1226. Philodryas patagoniensis - MZUFV 061, 062, 155, 336, 719, 1106, 1203, 1611, 1615. Pseudoboa nigra-MZUFV 1391. Sibynomorphus mikanii - IBSP 24324, 24325; MZUFV 122, 140, 142, 173, 252, 540, 1243, 1273, 1277, 1352, 1359, 1532, 1610, 1682. Sibynomorphus neuwiedi - MZUFV 016, 023-025, 079, 118, 134, 136, 158, 338, 356, 463, 469, 477, 481, 482, 516, 517, 538, 539. 542, 981, 987, 1022, 1032, 1190, 1274, 1518, 1566. Simophis rhinostoma - MZUFV 286, 364, 368, 527, 757, 829, 846, 911, $1305,1353$. Spilotes pullatus - MZUFV 1250, 1356, 1392. Taeniophallus affinis - MZUFV 448, 466, 1371, 1374, 1515, 1524. Taeniophallus occipitalis - MZUFV 449, 541, 479, 797, 832, 1384, 1385. Thamnodynastes nattereri - MZUFV 124, 128, 819. Tropidodryas striaticeps - MZUFV 059, 070, 092, 117, 318, 353, 443, 444, 528, 770, 773, 1083. Xenodon merremii- MZUFV 019, 026, 028, 039, 115, 126, 129, 137, 153, 432, $535,749,772,789,806,807,815,839,982,996,1020,1045,1299,1363,1421,1452,1553$. Xenodon nattereri - MZUFV 073. Xenodon neuwiedii - Parque Estadual da Serra do Brigadeiro, Araponga: MZUFV 808, 1122. 